\title{
Functional Connectivity of Multiple Brain Regions Required for the Consolidation of Social Recognition Memory
}

\author{
Toshiyuki Tanimizu, ${ }^{1}$ Justin W. Kenney, ${ }^{2}$ Emiko Okano, ${ }^{1}$ Kazune Kadoma, ${ }^{1}$ Paul W. Frankland, ${ }^{2}$ and $\mathbb{\complement}$ Satoshi Kida ${ }^{1,3}$ \\ ${ }^{1}$ Department of Biosciences, Faculty of Applied Bioscience, Tokyo University of Agriculture, Tokyo 156-8502, Japan, ${ }^{2}$ Program in Neurosciences and Mental \\ Health Program, The Hospital for Sick Children, Toronto M5G1X8, Canada, and ${ }^{3}$ Core Research for Evolutional Science and Technology (CREST), Japan \\ Science and Technology Agency, Saitama 332-0012, Japan
}

Social recognition memory is an essential and basic component of social behavior that is used to discriminate familiar and novel animals/humans. Previous studies have shown the importance of several brain regions for social recognition memories; however, the mechanisms underlying the consolidation of social recognition memory at the molecular and anatomic levels remain unknown. Here, we show a brain network necessary for the generation of social recognition memory in mice. A mouse genetic study showed that cAMPresponsive element-binding protein (CREB)-mediated transcription is required for the formation of social recognition memory. Importantly, significant inductions of the CREB target immediate-early genes c-fos and Arc were observed in the hippocampus (CA1 and CA3 regions), medial prefrontal cortex (mPFC), anterior cingulate cortex (ACC), and amygdala (basolateral region) when social recognition memory was generated. Pharmacological experiments using a microinfusion of the protein synthesis inhibitor anisomycin showed that protein synthesis in these brain regions is required for the consolidation of social recognition memory. These findings suggested that social recognition memory is consolidated through the activation of CREB-mediated gene expression in the hippocampus/mPFC/ACC/ amygdala. Network analyses suggested that these four brain regions show functional connectivity with other brain regions and, more importantly, that the hippocampus functions as a hub to integrate brain networks and generate social recognition memory, whereas the ACC and amygdala are important for coordinating brain activity when social interaction is initiated by connecting with other brain regions. We have found that a brain network composed of the hippocampus/mPFC/ACC/amygdala is required for the consolidation of social recognition memory.

Key words: brain network; consolidation; CREB; IEGs; social recognition memory

Significance Statement

Here, we identify brain networks composed of multiple brain regions for the consolidation of social recognition memory. We found that social recognition memory is consolidated through CREB-meditated gene expression in the hippocampus, medial prefrontal cortex, anterior cingulate cortex (ACC), and amygdala. Importantly, network analyses based on c-fos expression suggest that functional connectivity of these four brain regions with other brain regions is increased with time spent in social investigation toward the generation of brain networks to consolidate social recognition memory. Furthermore, our findings suggest that hippocampus functions as a hub to integrate brain networks and generate social recognition memory, whereas ACC and amygdala are important for coordinating brain activity when social interaction is initiated by connecting with other brain regions.

\section{Introduction}

Social behaviors contain multiple components including social approach, interaction, and recognition/discrimination (Thor and Holloway, 1982; Colgan, 1983; Lai et al., 2005; Gabor et al., 2012). In particular, social recognition memory is an essential and basic component of social behavior used to discriminate fa- 
A

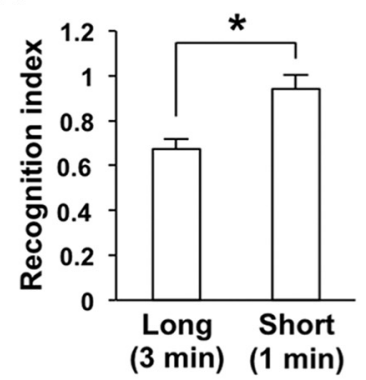

B

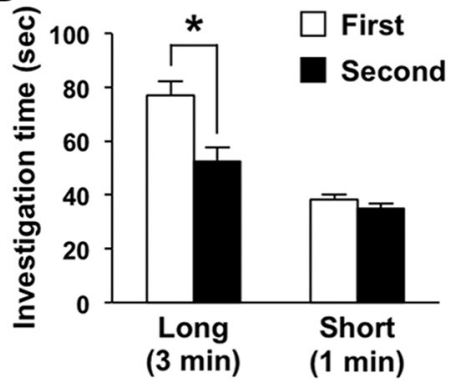

C

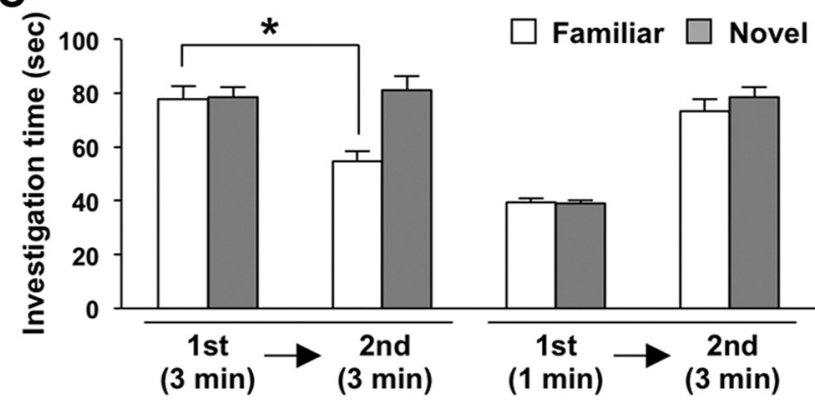

Figure 1. Exposure to a juvenile mouse for $3 \mathrm{~min}$, but not $1 \mathrm{~min}$, generates LTM of social recognition. $\boldsymbol{A}, \boldsymbol{B}$, Mice exposed to a juvenile male mouse twice for a long ( 3 min) or short ( 1 min) period with an interval of $24 \mathrm{~h}$. $\boldsymbol{A}$, Recognition index. ${ }^{*} p<0.05$ compared with the 1 min group. $\boldsymbol{B}$, Comparisons of social investigation time. 3 min group, $n=14 ; 1$ min group, $n=14$. ${ }^{*} p<0.05$ compared with the first exposure (paired $t$ test). $\boldsymbol{C}$, Mice exposed to a juvenile male mouse for 3 or 1 min and $24 \mathrm{~h}$ later, exposed to a familiar or novel juvenile for 3 min. ${ }^{*} p<0.05$ compared with the first exposure (paired $t$ test). 3 min-3 min: familiar group, $n=12$; novel group, $n=12 ; 1$ min -3 min: familiar group, $n=12$; novel group, $n=12$. Error bars indicate SEM.

miliar and novel animals/humans (Berry and Bronson, 1992; Jiming et al., 1994; Kogan et al., 2000).

Memory consolidation is the process underlying the formation of a long-term memory (LTM) by stabilizing a labile shortterm memory (STM) (Squire et al., 1995; Dudai, 1996; McGaugh, 2000). A critical biochemical feature of memory consolidation is the requirement for new gene expression (Flexner et al., 1965; Davis and Squire, 1984; Abel et al., 1997; Silva et al., 1998; Martin et al., 2000; McGaugh, 2000). Importantly, the gene expression necessary for consolidation is activated by transcription factor cAMP-responsive element-binding protein (CREB)-mediated transcription, which is known as a master regulator of neuralactivity-dependent transcription (Bourtchuladze et al., 1994; Kida et al., 2002; Pittenger et al., 2002; Josselyn et al., 2004; Kitamura et al., 2012).

CREB activates the expression of the immediate-early genes (IEGs) c-fos and Arc in an activity- and learning-dependent manner (Sheng et al., 1990; Abraham et al., 1993; Worley et al., 1993; Guzowski et al., 1999; Montag-Sallaz et al., 1999; Guthrie et al., 2000; Kaczmarek and Robertson, 2002; Kawashima et al., 2009). Importantly, abundant studies have shown that brain regions showing learning-induced IEG expression play essential roles in gene-expression-dependent memory processes including consolidation, reconsolidation, and extinction (Morrow et al., 1999; Santini et al., 2004; Mamiya et al., 2009; Zhang et al., 2011; Fukushima et al., 2014). Therefore, the expression of IEGs has been widely accepted as a marker to identify brain regions that are activated in response to learning or memory retrieval (Guzowski et al., 2001; Frankland et al., 2004; Frankland et al., 2006; Mamiya et al., 2009; Zhang et al., 2011; Fukushima et al., 2014).

Previous studies have shown that multiple brain regions regulate social behaviors and the formation of social recognition memory. The hippocampus, amygdala, and anterior cingulate cortex (ACC) are critical regions for the formation/consolidation of social recognition memory in mice (Kogan et al., 2000; Suzuki et al., 2011, Hitti and Siegelbaum, 2014, Garrido Zinn et al., 2016). Conversely, the medial prefrontal cortex (mPFC) and amygdala are involved in the regulation of social behaviors such as social interaction and approach. However, distinct roles for multiple brain regions in the consolidation of social recognition memory and connectivity of these regions to generate this memory remain unclear.

In the social recognition memory task in mice, an adult mouse is allowed to recognize a juvenile mouse through investigations of the juvenile mouse (Fukushima et al., 2008; Suzuki et al., 2011; Nomoto et al., 2012; Ishikawa et al., 2014; Inaba et al., 2016b).
The difference in social investigation times between the first and second exposures to a juvenile mouse reflects the familiarity of the two mice. In this study, to understand the mechanisms for the consolidation of social recognition memory at the anatomical level, we first clarified the brain regions required for the consolidation of social recognition memory by analyzing the expression of IEGs and then examining the effects of inhibiting gene expression on this process. Finally, we examined interregional functional connectivity using network analysis to gain further insight into how these brain regions work as a network to generate social recognition memory.

\section{Materials and Methods}

Animals. All experiments were conducted according to the Guide for the Care and Use of Laboratory Animals (Japan Neuroscience Society and Tokyo University of Agriculture). All animal experiments performed in this study were approved by the Animal Care and Use Committee of Tokyo University of Agriculture (authorization \#250008). All surgical procedures were performed under Nembutal anesthesia and every effort was made to minimize suffering. Male C57BL/6N mice were obtained from Charles River Laboratories. Transgenic mice expressing an inducible CREB repressor $\left(\mathrm{CREB}{ }^{\mathrm{IR}}\right.$ mice) were backcrossed to C57BL/6 (Kida et al., 2002; Suzuki et al., 2008; Mamiya et al., 2009; Fukushima et al., 2014). The mice were housed in groups of five or six, maintained on a $12 \mathrm{~h}$ light/dark cycle, and allowed ad libitum access to food and water. The mice were at least 8 weeks of age at the start of the experiments and all behavioral procedures were conducted during the light phase of the cycle. All experiments were conducted blinded to the treatment condition of the mice.

Social recognition task. The social recognition test was performed as described previously (Kogan et al., 2000; Fukushima et al., 2008; Suzuki et al., 2011; Nomoto et al., 2012; Ishikawa et al., 2014; Inaba et al., 2016b). Adult mice were placed into individual plastic cages in an experimental room under dim light. The cages were identical to those in which the mice were normally housed (plastic, $30 \times 17 \times 12 \mathrm{~cm}$ ). After a period of $60 \mathrm{~min}$, a juvenile mouse was placed into the cage with a subject for a first-exposure trial lasting 0,1 , or $3 \mathrm{~min}$. The duration of social investigation behavior exhibited by the adult mouse was determined with a hand-held stopwatch. Social investigation was measured as described previously (Thor and Holloway, 1982). Memory was reassessed $2 \mathrm{~h}$ (STM) or $24 \mathrm{~h}$ (LTM) later by recording the length of investigation time exhibited by the subject to a familiar (same) or novel (new) juvenile (second exposure). To evaluate the differences of ability to form social memory between the groups of mice, we calculated a recognition index: the ratio of the duration of the second and first investigation times.

For the first experiment (Fig. 1A,B), we investigated the training condition that allows mice to form social recognition memory. Mice were exposed to a juvenile mouse twice for 1 or $3 \mathrm{~min}$ at an interval of 24 h. 
A

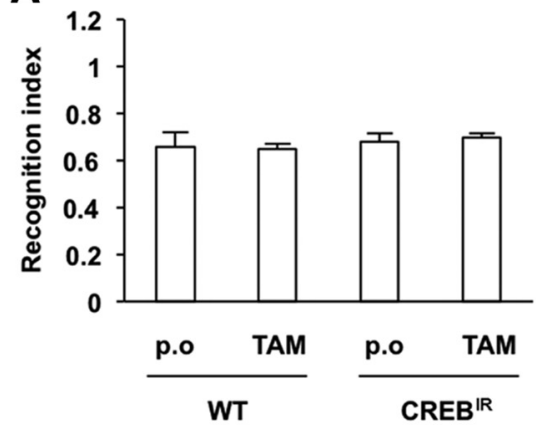

C

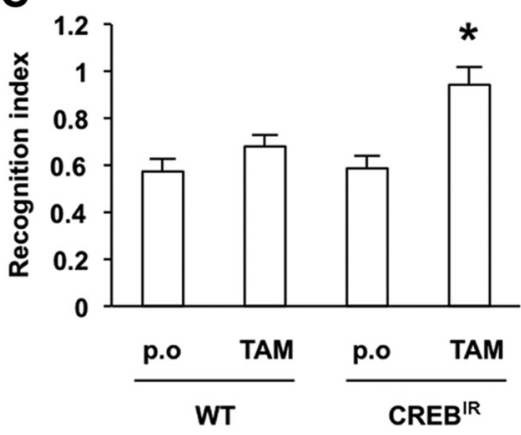

B
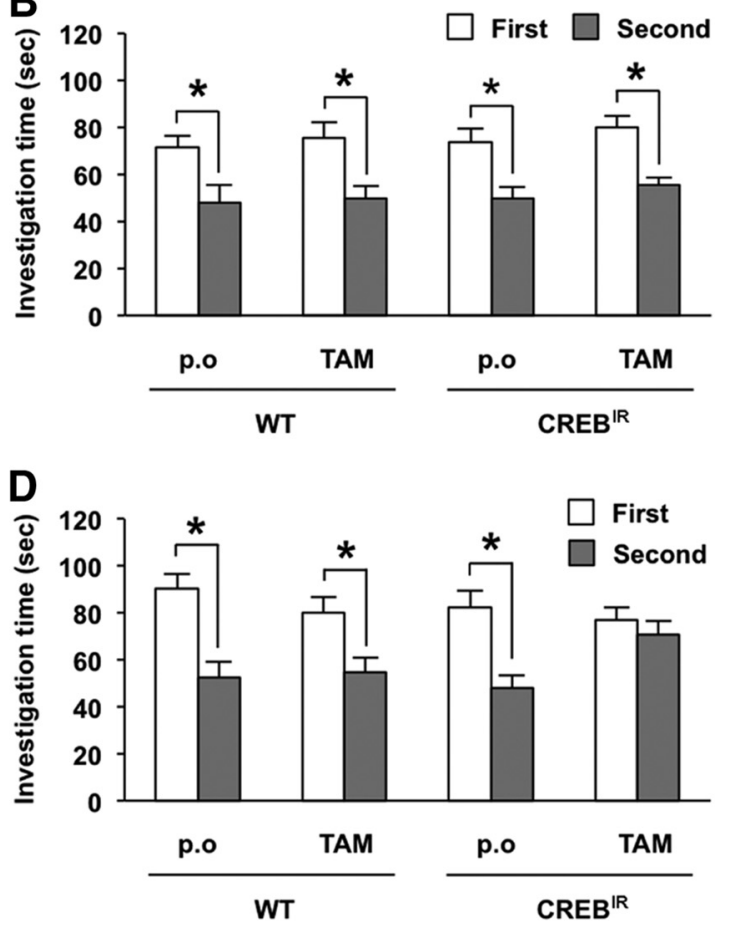

Figure 2. CREB-mediated transcription is required for the formation of social recognition LTM. $A, B$, Social recognition STM. WT/p.0, $n=6 ; \mathrm{WT} / \mathrm{TAM}, n=6 ; \mathrm{CREB}^{\mathrm{IR}} / \mathrm{p} .0, n=6 ; \mathrm{CREB}^{\mathrm{IR}} / \mathrm{TAM}$, $n=6$. C, D, Social recognition LTM. WT/p.o, $n=12$; WT/TAM, $n=14$; CREB ${ }^{\mathrm{IR}} / \mathrm{p} .0, n=12 ;$ CREB $^{\mathrm{IR}} / \mathrm{TAM}, n=12$. $\boldsymbol{A}, \boldsymbol{C}$, Recognition index. ${ }^{*} p<0.05$ compared with the other groups. $\boldsymbol{B}, \boldsymbol{D}$, Investigation time. ${ }^{*} p<0.05$ compared with the first exposure (paired $t$ test). Error bars indicate SEM.

For the second experiment, we investigated whether 1 min exposure to a juvenile mouse enables the generation of social recognition memory (Fig. 1C). The mice were exposed to a juvenile mouse for $3 \mathrm{~min}$ or $1 \mathrm{~min}$ at the first exposure and, $24 \mathrm{~h}$ later, were exposed to a familiar or novel juvenile mouse for $3 \mathrm{~min}$ (second exposure).

For the third experiment (Fig. 2), transgenic mice were used that express an inducible CREB repressor $\left(\mathrm{CREB}^{\mathrm{IR}}\right)$ in the forebrain, where a dominant-negative CREB protein is fused with the ligandbinding domain of a mutant estrogen receptor. As described previously, systemic injection of tamoxifen into these transgenic mice inhibits CREB activity in the forebrain (Kida et al., 2002). CREB ${ }^{\text {IR }}$ and wild-type (WT) mice were administered an intraperitoneal injection of $16 \mathrm{mg} / \mathrm{kg}$ 4-hydroxytamoxifen (TAM; Sigma-Aldrich), which was dissolved in $10 \mathrm{ml}$ of peanut oil (p.o; Sigma-Aldrich), or vehicle (VEH; a similar volume of peanut oil) at $6 \mathrm{~h}$ before the first exposure (Kida et al., 2002; Suzuki et al., 2008; Mamiya et al., 2009; Fukushima et al., 2014). At 2 or $24 \mathrm{~h}$ after the first exposure session, the mice received the second exposure.

For the fourth experiment (immunohistochemistry of c-fos and Arc; Figs. 3,4 ), the mice were divided into 4 groups: 3 , 1 , and 0 min groups were exposed to a juvenile mouse for 3,1 , or $0 \mathrm{~min}$, respectively (the 0 min group was placed into individual plastic cages, but not exposed to a juvenile mouse). These groups were perfused at $90 \mathrm{~min}$ after exposure. The home cage group was left undisturbed in their home cage throughout the experiment and anesthetized, as above, after they were taken from their home cages.

For the fifth experiment (Figs. 5, 6), the mice were trained as described above and received a microinfusion of the protein synthesis inhibitor anisomycin (ANI, $62.5 \mu \mathrm{g}$; Sigma-Aldrich) or artificial CSF (ACSF) into the hippocampus, $\mathrm{mPFC}$, ACC, or amygdala immediately after the first exposure. At 2 or $24 \mathrm{~h}$ after the first exposure session, the mice received the second exposure. ANI was dissolved in vehicle solution (ACSF) and adjusted to $\mathrm{pH} 7.0-7.4$ with $\mathrm{NaOH}$.

Immunohistochemistry. Immunohistochemistry was performed as described previously (Mamiya et al., 2009; Suzuki et al., 2011; Zhang et al., 2011; Fukushima et al., 2014; Inaba et al., 2015 and 2016a). After anes- thetization, all mice were perfused with $4 \%$ paraformaldehyde. Brains were then removed, fixed overnight, transferred to $30 \%$ sucrose, and stored at $4^{\circ} \mathrm{C}$. Coronal sections $(30 \mu \mathrm{m})$ were cut in a cryostat. The sections were pretreated with $4 \%$ paraformaldehyde for $20 \mathrm{~min}$ and $3 \%$ $\mathrm{H}_{2} \mathrm{O}_{2}$ in methanol for $1 \mathrm{~h}$, followed by incubation in blocking solution (PBS plus $1 \%$ goat serum albumin, $1 \mathrm{mg} / \mathrm{ml}$ bovine serum albumin, and $0.05 \%$ Triton X-100) for $3 \mathrm{~h}$ at $4^{\circ} \mathrm{C}$. Consecutive sections were incubated with a polyclonal rabbit primary antibody for anti-c-fos (1:5000; Millipore catalog \#PC38, RRID: AB_2106755) or anti-Arc (1:1000; Santa Cruz Biotechnology catalog \#sc-15325, RRID: AB_634092) in the blocking solution for 2 nights at $4^{\circ} \mathrm{C}$. Subsequently, the sections were washed with PBS and incubated for $4 \mathrm{~h}$ at room temperature with biotinylated goat anti-rabbit IgG (SAB-PO kit; Nichirei Biosciences), followed by $1 \mathrm{~h}$ at room temperature in the streptavidin-biotin-peroxidase complex (SAB-PO kit). Immunoreactivity was detected with a DAB substrate kit (Nichirei Biosciences). Structures were anatomically defined according to the atlas of Franklin and Paxinos (1997). Quantification of c-fos- or Arc-positive cells in sections $(100 \times 100 \mu \mathrm{m})$ of the olfactory bulb (OB; bregma between +4.28 and $+3.92 \mathrm{~mm}$ ), $\mathrm{mPFC}$ (bregma between +2.10 and $+1.98 \mathrm{~mm}$ ), ACC (bregma between +0.8 and +1.0$)$, medial preoptic area (MPOA; bregma between +0.14 and $+0.02 \mathrm{~mm}$ ), amygdala (bregma between -1.22 and $-1.34 \mathrm{~mm}$ ), dorsal hippocampus (bregma between -1.46 and $-1.82 \mathrm{~mm}$ ), visual cortex (VC; bregma between -3.88 and -4.00 ), temporal cortex (TC; bregma between -3.88 and $-4.00)$, perirhinal cortex (PRh; bregma between -3.88 and -4.00$)$, and entorhinal cortex (EC; bregma between -3.88 and -4.00 ) was performed using a computerized image analysis system (WinROOF version 5.6 software; Mitani). Immunoreactive cells were counted bilaterally with a fixed sample window across at least three sections by an experimenter blinded to the treatment condition. The number of c-fos- or Arc-positive cells in each group was expressed as the ratio of the averaged values in the home cage control group.

Surgery for drug microinfusion. Surgeries were performed as described previously (Suzuki et al., 2008; Mamiya et al., 2009; Suzuki et al., 2011; Zhang et al., 2011; Fukushima et al., 2014; Guimaraes et al., 2015; Inaba et al., 2015 and 2016a). Under Nembutal anesthesia and using standard 
A

hippocampus (CA1)
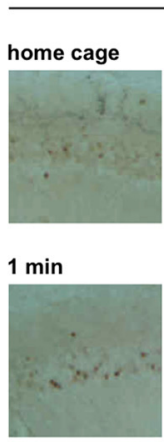
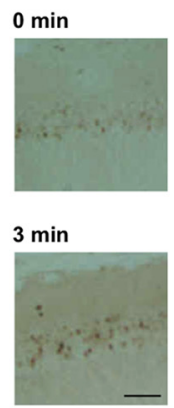

mPFC (PL)
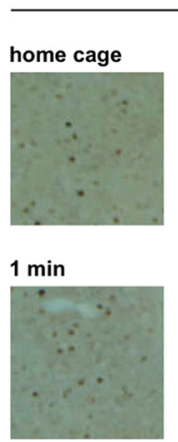

$0 \mathrm{~min}$

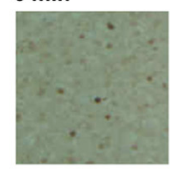

$3 \mathrm{~min}$

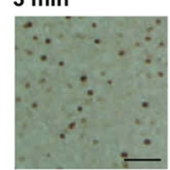

ACC

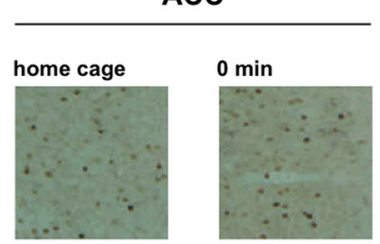

$1 \mathrm{~min}$

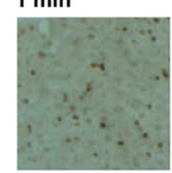

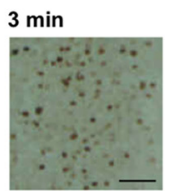

amygdala (BLA)
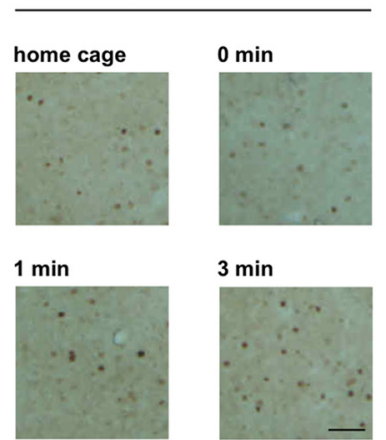

B

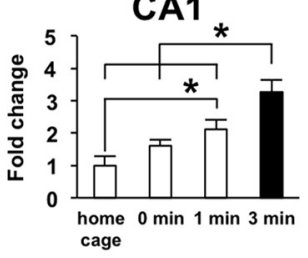

D

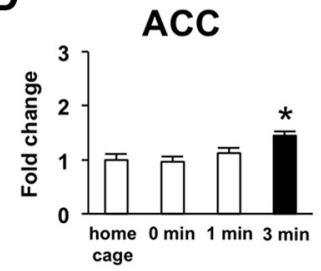

F

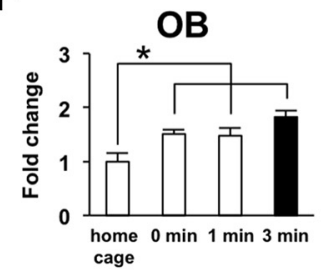

H

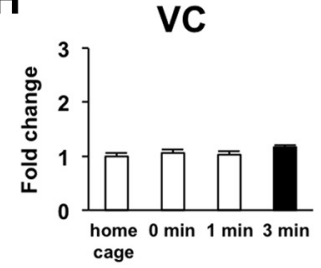

CA3

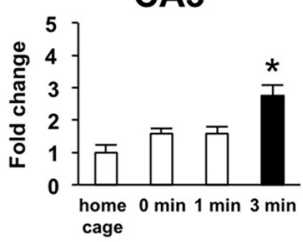

E

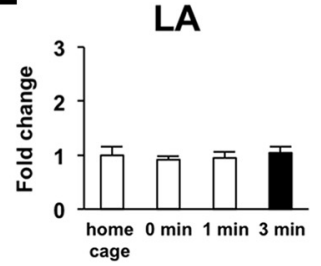

G

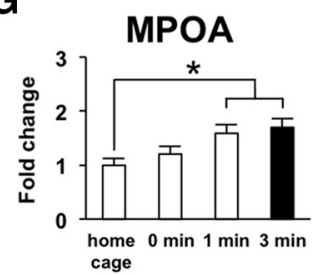

C

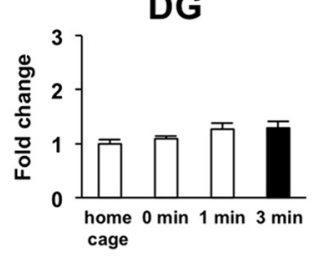

BLA

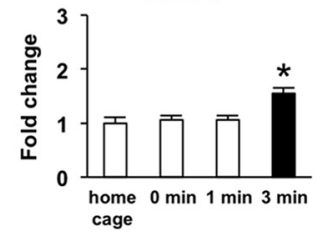

PL

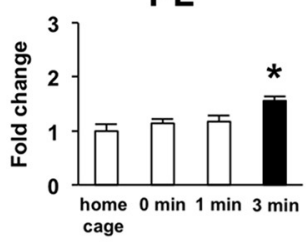

IL

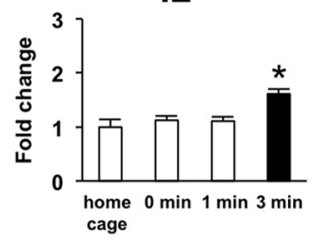

CeA

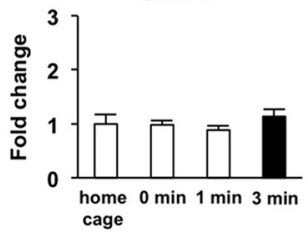

PRh
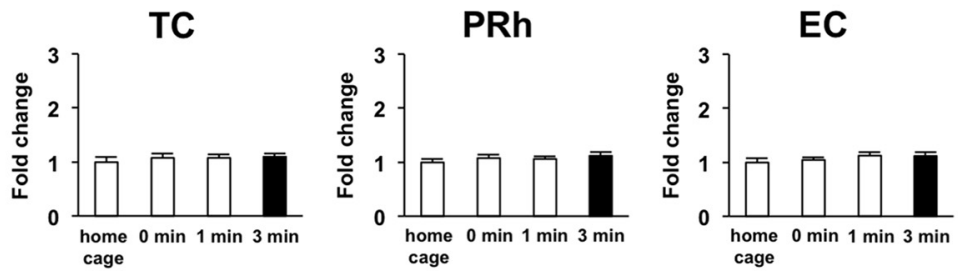

Figure 3. c-fos expression in distinct brain regions after exposure to a juvenile mouse. $A$, Representative immunohistochemical staining of $C A 1$, $P L$, $A C C$, and $B L A$ c-fos-positive cells from the indicated mice. Scale bar, $50 \mu \mathrm{m}$. $\boldsymbol{B}$ - $\boldsymbol{H}$, Number of c-fos-positive cells was measured after exposure to a juvenile mouse for 0,1, or 3 min or remaining in the home cage. $\boldsymbol{B}$, CA1, CA3, and DG regions of the hippocampus. C, PL and IL regions of the mPFC. $\boldsymbol{D}, A C C$. $\boldsymbol{E}, \mathrm{LA}, \mathrm{BLA}$, and CeA regions of the amygdala. $\boldsymbol{F}, 0 \mathrm{~B}$. G, MPOA. $\boldsymbol{H}, \mathrm{VC}, \mathrm{TC}, \mathrm{PRh}$, and EC regions of the cortex. $C$-fos expression for each group is expressed as the ratio of the home cage group to the other groups. Home cage, $n=12 ; 0$ min, $n=11 ; 1$ min, $n=12 ; 3$ min, $n=12$. ${ }^{*} p<0.05$ compared within the group. Error bars indicate SEM.

stereotaxic procedures, stainless steel guide cannulae (22 gauge) were implanted into the dorsal hippocampus $(-1.8 \mathrm{~mm}, \pm 1.8 \mathrm{~mm},-1.9$ $\mathrm{mm}), \operatorname{mPFC}(2.7 \mathrm{~mm}, \pm 0 \mathrm{~mm},-1.6 \mathrm{~mm})$, ACC $(1.8 \mathrm{~mm}, \pm 0 \mathrm{~mm},-1.6$ $\mathrm{mm})$, or amygdala $(-1.3 \mathrm{~mm}, \pm 3.3 \mathrm{~mm},-4.4 \mathrm{~mm})$. The mice were allowed to recover for at least 1 week after surgery. After this, they were handled for 1 week before the commencement of the social recognition task. Infusions into the dorsal hippocampus, mPFC, ACC, or amygdala $(0.5 \mu \mathrm{l})$ were made at a rate of $0.25 \mu \mathrm{l} / \mathrm{min}$. This dose of locally infused ANI inhibits $>90 \%$ of protein synthesis for at least $4 \mathrm{~h}$ (Rosenblum et al.,
1993). Cannula tip placements are shown in Figures $5 I$ and $6 I$. Only mice with a cannula tip within the boundaries of the hippocampus, mPFC, ACC, or amygdala were included in the data analysis.

Network construction and graph theoretical analysis. Correlation matrices were generated using Pearson $r$ values from interregional c-fos expression data at 0,1 , and $3 \mathrm{~min}$ (Fig. 7A). For comparisons of average correlations between groups, Pearson $r$ values were Fisher $z$-transformed, statistics were calculated, and the data were retransformed back to $r$ values. All interregional correlations between hippocampal, $\mathrm{mPFC}, \mathrm{ACC}$, or amygdala regions 


\section{A}

hippocampus (CA1)

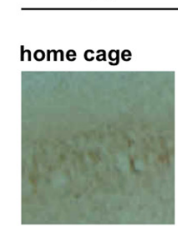

$1 \mathrm{~min}$

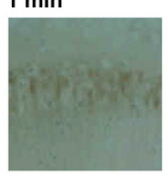

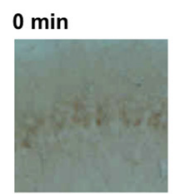

$3 \mathrm{~min}$

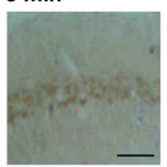

mPFC (PL)

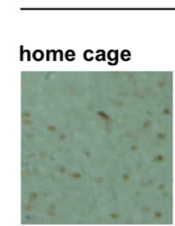

$1 \mathrm{~min}$

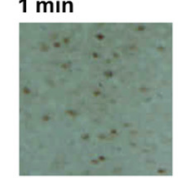

B

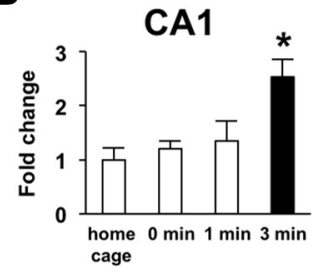

D

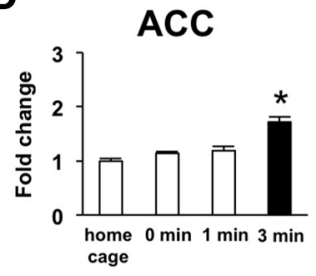

F

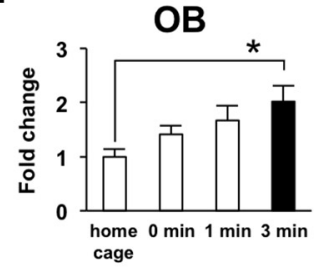

H

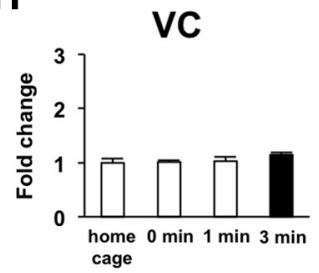

CA3

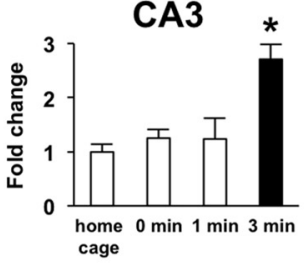

E

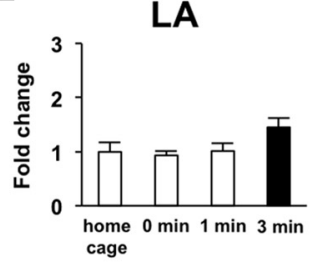

G

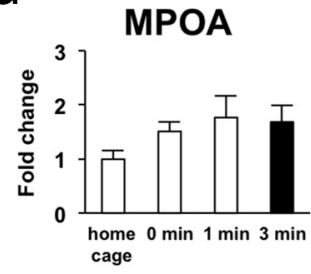

ACC
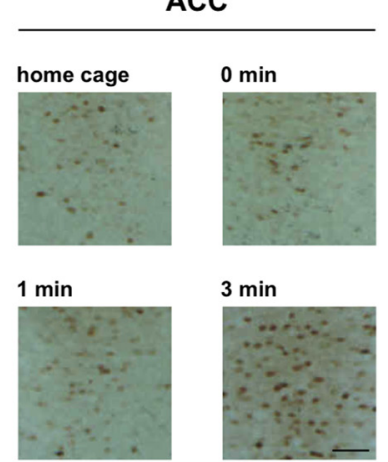

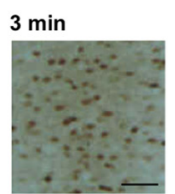

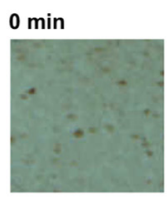

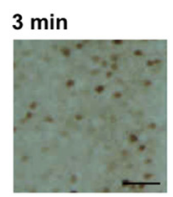

C
DG

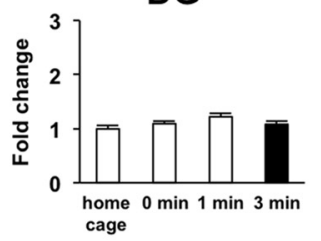

PL

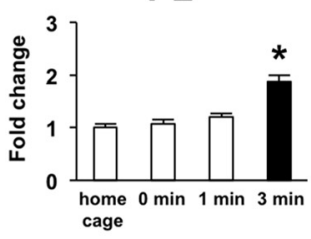

amygdala (BLA)
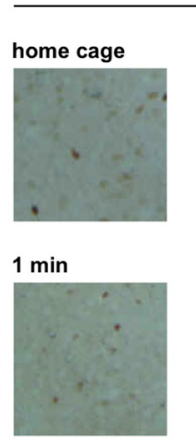

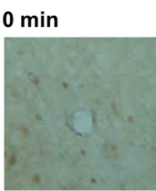

$3 \mathrm{~min}$

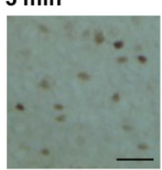

IL

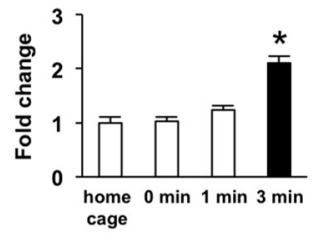

BLA

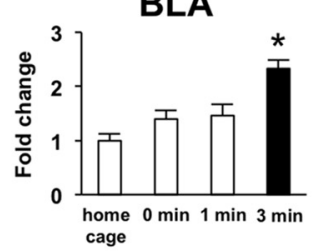

CeA

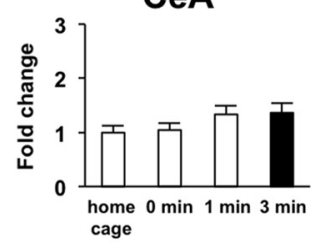

TC

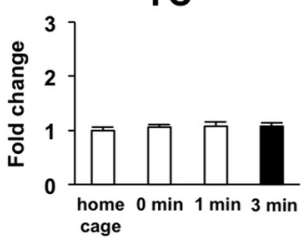

PRh
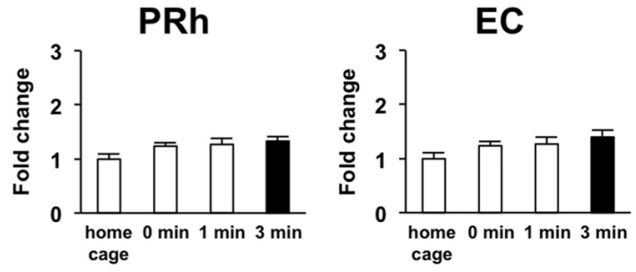

Figure 4. Arc expression in distinct brain regions after exposure to a juvenile mouse. $A$, Representative immunohistochemical staining of CA1, PL, ACC, and BLA Arc-positive cells from the indicated mice. Scale bar, $50 \mu \mathrm{m} . \boldsymbol{B}-\boldsymbol{H}$, Number of Arc-positive cells measured after exposure to a juvenile mouse for 0,1 , or 3 min or remaining in the home cage. $\boldsymbol{B}$, CA1, CA3, and DG regions of the hippocampus. C, PL and IL regions of the mPFC. D, ACC. E, LA, BLA, and CeA regions of the amygdala. F, OB. G, MPOA. H, VC, TC, PRh, and EC regions of the cortex. Arc expression for each group is expressed as the ratio of the home cage group to the other groups. Home cage, $n=12 ; 0 \mathrm{~min}, n=12 ; 1 \mathrm{~min}, n=12 ; 3 \mathrm{~min}, n=12 .{ }^{*} p<0.05$ compared within the group. Error bars indicate SEM.

were used to assess time-dependent changes in functional connectivity (Fig. $7 D-K)$.

Graph theoretical analysis was used to characterize the social recognition memory networks. Networks were constructed by thresholding correlations of interregional c-fos counts at an uncorrected significance level of $p<0.05$ to generate unweighted adjacency matrices for the 0,1 , and 3 min groups. The centrality measures of degree and betweenness were calculated and normalized to the maximum and minimum values for each individual network. Clusters were identified through enumeration of all potential community structures and finding the configuration that optimized the modularity (Newman and Girvan, 2004). Measures of within-community (within-module $z$-scores) and between-community (participation coefficient) connectivity were calculated as defined in Guimerà and Amaral (2005). All graph theoretical analysis was performed in R (version 3.2.2) using the igraph (version 1.0.1; Csardi and Nepusz, 2006) and brainGraph (version 0.62.0) packages. Graph visualization was performed using Cytoscape (version 3.2.1; Shannon et al., 2003).

Data analysis. One-way or two-way factorial ANOVA followed by a post hoc Newman-Keuls comparison were used to analyze the effects of time, genotype, group, and drug. A paired $t$ test was used to analyze the 
hippocampus
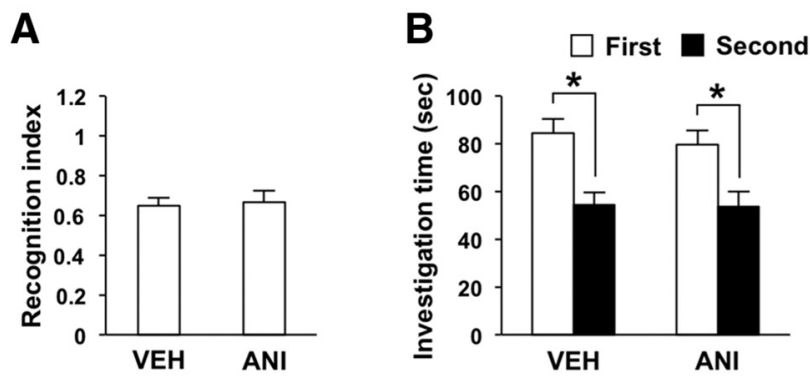

ACC
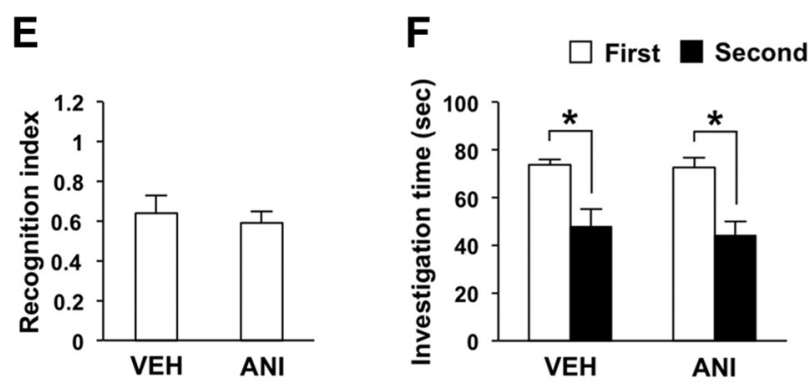

\section{MPFC}
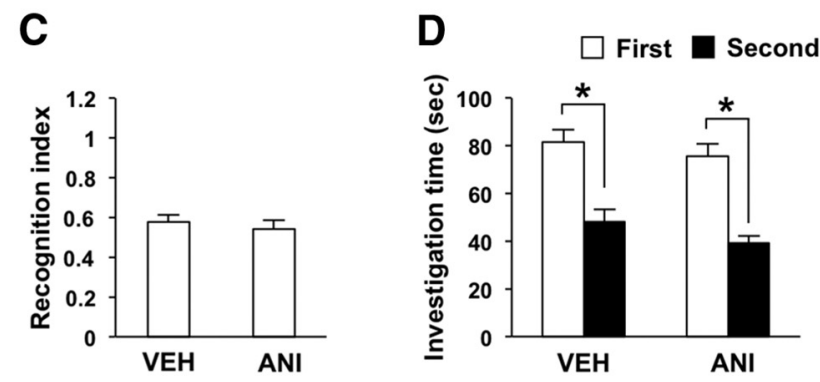

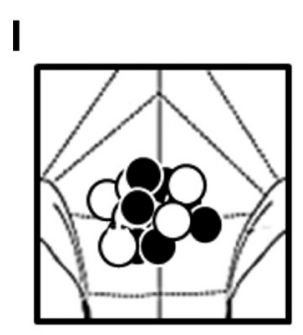

MPFC

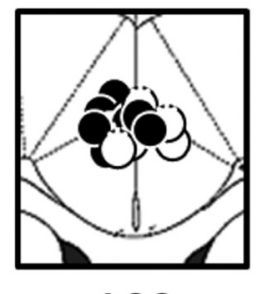

ACC

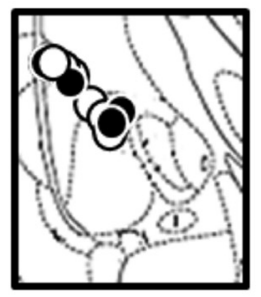

amygdala
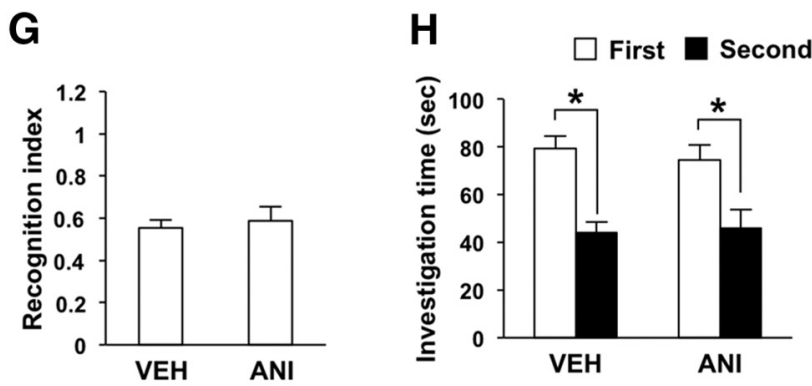

Figure 5. Protein synthesis in the hippocampus, $\mathrm{mPFC}, \mathrm{ACC}$, and amygdala is not required for social recognition STM. $A, \boldsymbol{B}$, Protein synthesis inhibition in the hippocampus. VEH, $n=12 ; \mathrm{ANI}, n=$ 12. C, D, mPFC. VEH, $n=12 ; \mathrm{ANI}, n=11$. (E, $\boldsymbol{F})$ ACC. VEH, $n=12 ; \mathrm{ANI}, n=12 . \mathbf{G}, \boldsymbol{H}$, amygdala. VEH, $n=11 ; \mathrm{ANI}, n=11 . \boldsymbol{A}, \boldsymbol{C}, \boldsymbol{E}, \mathbf{G}$, Recognition index. ${ }^{*} p<0.05$ compared with the VEH group. $\boldsymbol{B}, \boldsymbol{D}, \boldsymbol{F}, \boldsymbol{H}$, Comparisons of social investigation time. ${ }^{*} p<0.05$ compared with the first exposure (paired $t$ test). Error bars indicate SEM. I, Cannula tip placements.

differences in social investigation times within each group between the first and second exposure in the social recognition task. All values in the text and figure legends represent the mean \pm SEM.

\section{Results}

Formation of social recognition memory after exposure to a juvenile mouse for $3 \mathrm{~min}$, but not $1 \mathrm{~min}$

We first investigated whether the training conditions used in this study enabled mice to form social recognition memory. Similar to our previous studies (Fukushima et al., 2008; Suzuki et al., 2011; Nomoto et al., 2012; Ishikawa et al., 2014; Inaba et al., 2016b), adult male mice were exposed to a juvenile male mouse twice for a long period $(3 \mathrm{~min})$ or a short period $(1 \mathrm{~min})$ at an interval of $24 \mathrm{~h}$ and the time taken to investigate the juvenile during the first (training) and second (test) exposures was assessed. To evaluate the strength of social recognition memory, we assessed the recognition index (Fukushima et al., 2008; Suzuki et al., 2011), the ratio of the second and first investigation time. One-way ANOVA followed by a post hoc Newman-Keuls test revealed significant effects of exposure time (Fig. $1 A, F_{(1,26)}=$ $12.147, p<0.05)$. The 3 min group showed a significantly better recognition index than the 1 min group (Fig. $1 A, p<0.05$ ), suggesting that the 3 min group formed a stronger social recognition memory than the $1 \mathrm{~min}$ group. Consistently, the $3 \mathrm{~min}$ group, but not the 1 min group, showed a significant decrease in social investigation time at the second exposure compared with the first exposure (Fig. $1 B$; paired $t$ test, $p<0.05$ ), suggesting that only the 3 min group formed a social memory. These results suggest that mice form a social recognition memory when they are exposed to a juvenile mouse for $3 \mathrm{~min}$, but not for $1 \mathrm{~min}$.

However, the possibility remained that a short exposure (1 $\min$ ) to a juvenile mouse is sufficient to generate a social memory, but the social memory is masked because the 1 min exposure is too short to allow us to identify a decrease in social investigation time at the second exposure. To address this possibility, similar to the previous experiment (Fig. $1 A, B$ ), adult mice were exposed to a juvenile male mouse for $3 \mathrm{~min}$ or $1 \mathrm{~min}$ at the first 


\section{hippocampus}

A

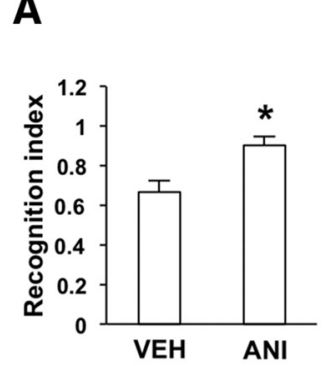

B

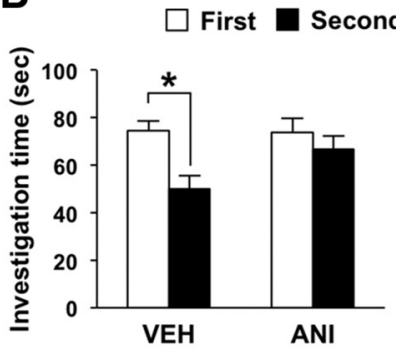

ACC

E

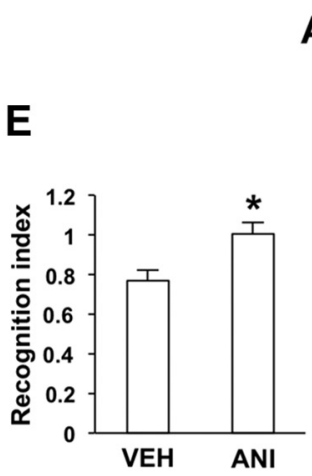

$\mathbf{F}$

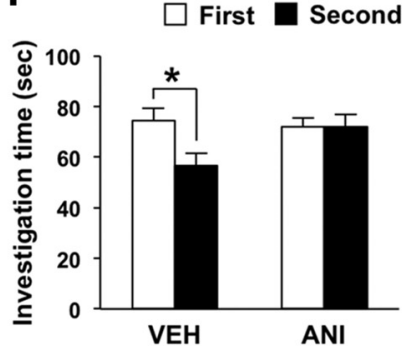

C

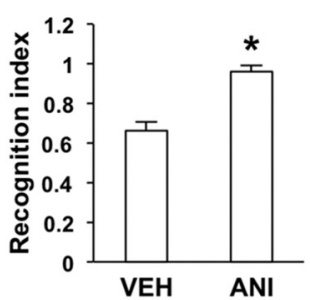

mPFC

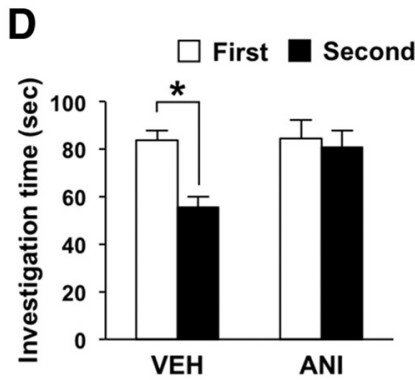

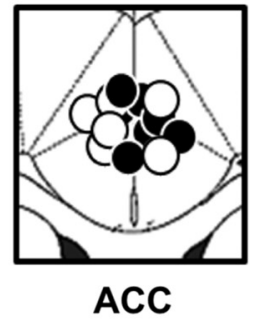

ACC

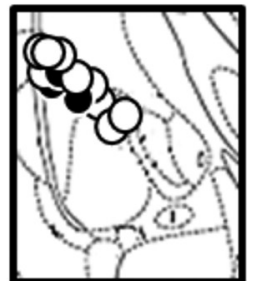

amygdala
G

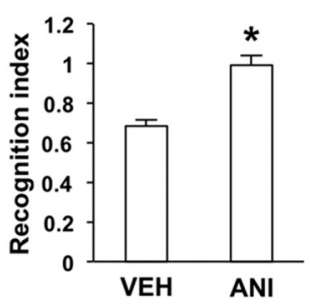

First

Second

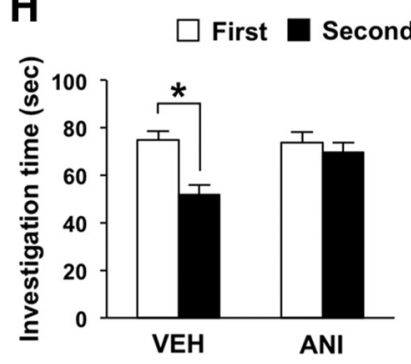

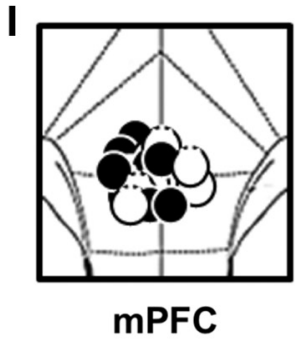

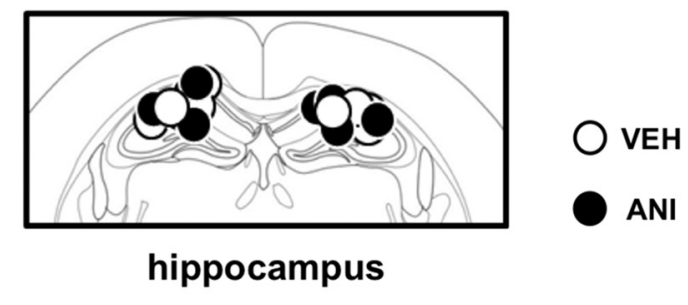

Figure 6. Protein synthesis in the hippocampus, $\mathrm{MPFC}, \mathrm{ACC}$, or amygdala is required for social recognition $\mathrm{LTM}$. $\boldsymbol{A}, \boldsymbol{B}$, Protein synthesis inhibition in the hippocampus. VEH, $n=12 ; \mathrm{ANI}, n=12$. $\boldsymbol{C}, \boldsymbol{D}, \mathrm{mPFC}$. VEH, $n=12 ; \mathrm{ANI}, n=10 . \boldsymbol{E}, \boldsymbol{F}, \mathrm{ACC}$. VEH, $n=14 ;$ ANI, $n=13$. $\mathbf{G}, \boldsymbol{H}$, Amygdala. VEH, $n=11 ; \mathrm{ANI}, n=12 . \boldsymbol{A}, \boldsymbol{C}, \boldsymbol{E}, \mathbf{G}, \mathbf{R e c o g n i t i o n}$ index. ${ }^{*} p<0.05$ compared with the VEH group. $\boldsymbol{B}, \boldsymbol{D}$, $\boldsymbol{F}, \boldsymbol{H}$, Comparisons of social investigation time. ${ }^{*} p<0.05$ compared with the first exposure (paired $t$ test). Error bars indicate SEM. $\boldsymbol{I}$, Cannula tip placements.

exposure, but were exposed to the familiar or novel juvenile male mouse for $3 \mathrm{~min}$, but not $1 \mathrm{~min}$, at $24 \mathrm{~h}$ after the first exposure (second exposure). Consistent with the previous observation, mice exposed to a juvenile mouse for $3 \mathrm{~min}$ at the first exposure showed a significant decrease in investigation time at the second exposure when they were exposed to a familiar, but not novel, mouse (Fig. 1C, $p<0.05$ ) and, importantly, showed significantly less investigation time for a familiar mouse compared with a novel mouse, indicating that 3 min groups formed a social recognition memory and discriminated familiar and novel mice. In contrast, the 1 min group showed comparable investigation time to familiar and novel mice even when they were exposed to the mice for $3 \mathrm{~min}$ at the second exposure, indicating that the 1 min group failed to discriminate familiar and novel mice. These results suggest that a $1 \mathrm{~min}$ exposure to a juvenile mouse is insufficient to allow mice to form a social recognition memory. According to these findings, we used the 1 min group as a negative control that was unable to form a social recognition memory when exposed to a juvenile mouse.
Role of CREB-mediated transcription in the consolidation of social recognition memory

CREB-mediated transcription is required for the consolidation of fear, conditioned taste avoidance, and spatial memories (Kida et al., 2002; Josselyn et al., 2004; Kitamura et al., 2012). To understand the molecular mechanisms underlying the consolidation of social recognition memory, we examined the effects of loss-ofCREB function using CREB $^{\mathrm{IR}}$ transgenic mice (Kida et al., 2002). $\mathrm{CREB}^{\mathrm{IR}}$ and WT littermate controls mice were exposed to a juvenile male mouse twice for $3 \mathrm{~min}$ at an interval of $2 \mathrm{~h}$ (STM) or $24 \mathrm{~h}$ (LTM). Six hours before the first exposure, the mice received a systemic injection of TAM or VEH to inhibit CREB activity (Kida et al., 2002).

Two-way ANOVA comparing recognition index of STM revealed no significant effect of genotype (WT vs CREB ${ }^{\mathrm{IR}}$ ) or drug (VEH vs TAM) and no genotype versus drug interaction (Fig. $2 A$, genotype, $F_{(1,20)}=0.775, p>0.05$; drug, $F_{(1,20)}=0.023, p>0.05$; genotype vs drug, $\left.F_{(1,20)}=0.123, p>0.05\right)$, suggesting that TAM-injected CREB ${ }^{\mathrm{IR}}$ mice showed normal STM. Consistently, TAM-injected CREB ${ }^{\mathrm{IR}}$ mice and other control mice showed a 
A

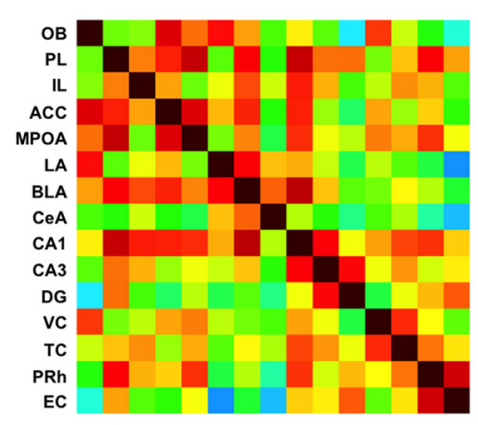

B

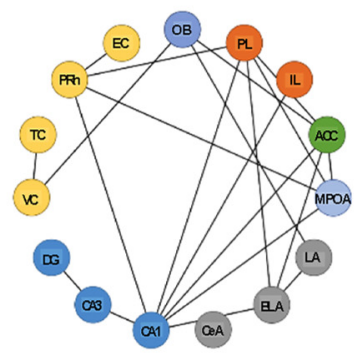

1 min
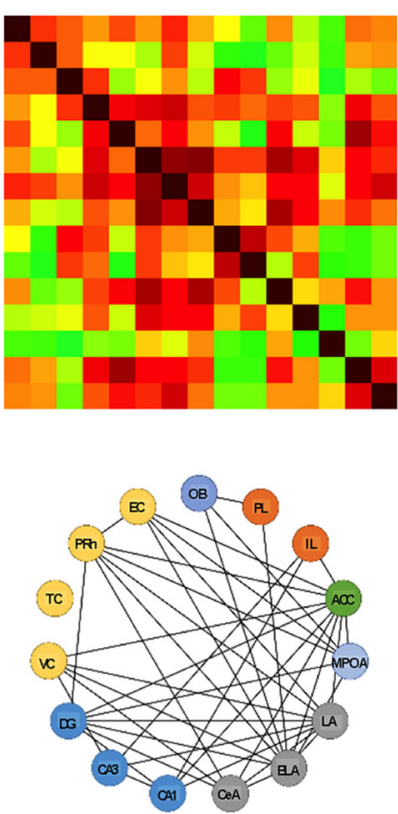

$3 \min$

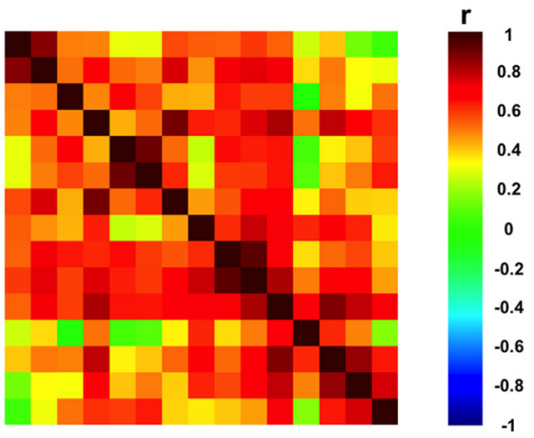

C

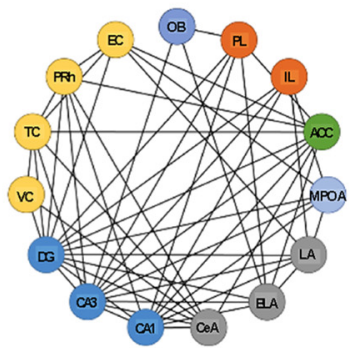

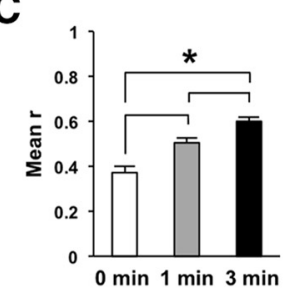

MPFC

hippocampus

D

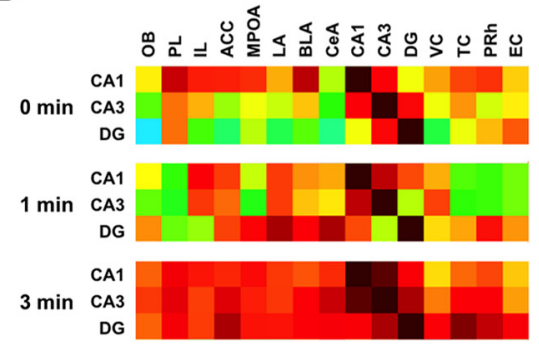

ACC

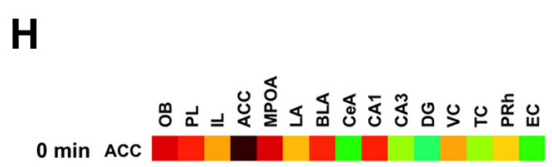

$1 \mathrm{~min}$ ACC

$3 \mathrm{~min}$ ACC
E

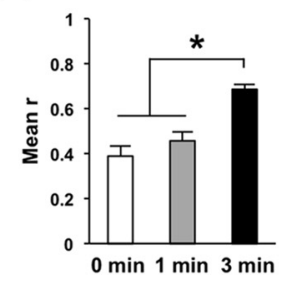

F

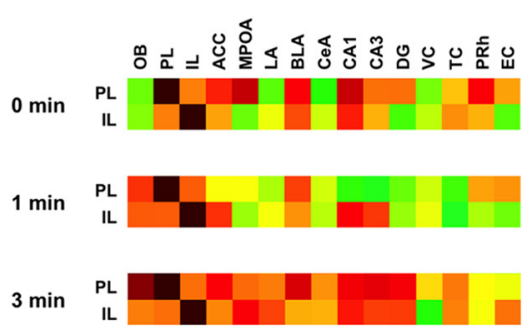

G

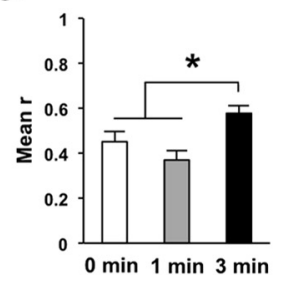

amygdala

I

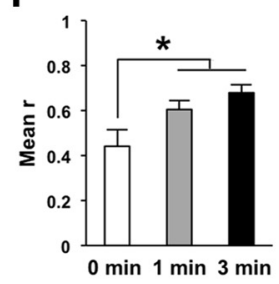

J

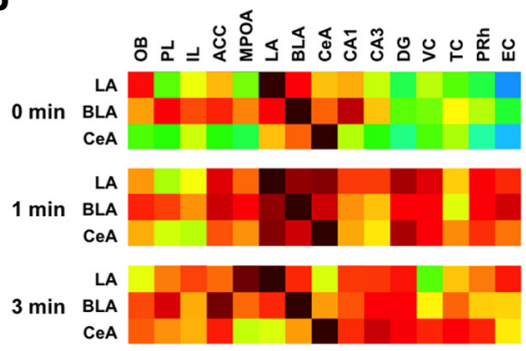

K

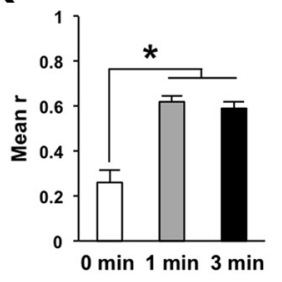

Figure 7. Generation of social recognition memory networks. $A$, Matrices showing interregional correlations for $c$-fos expression at 0,1 , or 3 min exposure. Colors reflect correlation strength based on Pearson's $r$ (scale, right). $\boldsymbol{B}$, Network graphs were generated by significant positive correlations $(p<0.05)$. $\boldsymbol{C}$, Mean $r$ was calculated from all interregional correlation coefficients. ${ }^{*} p<0.05$ compared within the group. $\boldsymbol{D}, \boldsymbol{F}, \boldsymbol{H}, \boldsymbol{J}$, Color-coded matrices showing interregional correlations for c-fos expression between the hippocampus $(\boldsymbol{D}), \mathrm{mPFC}(\boldsymbol{F}), \mathrm{ACC}(\boldsymbol{H})$, or amygdala $(\boldsymbol{J})$ and other regions in the 0,1 , and 3 min groups. $E, G, I, K$, Mean $r$ was calculated from interregional correlation coefficients. ${ }^{*} p \leq 0.05$ compared within the group. Error bars indicate $S E M$.

significant decrease in social investigation time at the second exposure compared with the first exposure (Fig. $2 B$, paired $t$ test, $p<0.05)$.

In contrast to the results for STM, two-way ANOVA comparing recognition index of LTM revealed significant effects of genotype and drug and a genotype versus drug interaction (genotype, $F_{(1,46)}=5.193, p<0.05$; drug, $F_{(1,46)}=14.938, p<0.05$; genotype vs drug, $\left.F_{(1,46)}=4.41, p<0.05\right)$. Importantly, TAM- injected CREB ${ }^{\mathrm{IR}}$ mice showed a significantly worse recognition index than the other groups (Fig. $2 C$; $p<0.05$ ). Consistently, only TAM-injected CREB ${ }^{\mathrm{IR}}$ mice failed to show a significant decrease in social investigation time at the second exposure (Fig. $2 D$; paired $t$ test, $p>0.05$ ). These results indicated that the inhibition of CREB-mediated transcription in the forebrain blocked the formation of long-term social recognition memory without affecting short-term social recognition memory, suggesting that 
activation of CREB-mediated transcription is required for the consolidation of social recognition memory.

\section{Induction of c-fos expression in multiple brain regions after training for social recognition}

To identify the brain regions expressing IEGs targeted by CREB when social recognition memory is generated, we performed immunohistochemistry to measure the expression of c-fos. We prepared 4 experimental groups $(3,1$, and 0 min exposure and home cage groups). Similar to Figure 1, the mice were exposed to a juvenile male mouse for $3 \mathrm{~min}$ or $1 \mathrm{~min}$ and only the 3 min group formed a social memory. The other groups of mice were exposed to the investigation cage (novel environment) without exposure to a juvenile male mouse ( 0 min group) or stayed in their home cages when the other groups of mice $(0,1$, and 3 min groups) underwent exposure. The number of c-fos-positive cells was measured in the hippocampus [CA1, CA3, and dentate gyrus (DG) regions], mPFC [prelimbic (PL) and infralimbic (IL) regions], ACC, amygdala [lateral (LA), basolateral (BLA), and central (CeA) regions], OB, MPOA, and other cortical regions (VC, TC, PRh, and EC) at 90 min after the exposure session.

One-way ANOVA revealed significant effects of group on the CA1, CA3, PL, IL, ACC, and BLA regions, but not on the DG, LA, and CeA regions (Fig. $3 B-E$; CA1, $F_{(3,43)}=10.427, p<0.05$; CA3, $F_{(3,43)}=9.166, p<0.05 ; \mathrm{PL}, F_{(3,43)}=5.564, p<0.05 ; \mathrm{IL}, F_{(3,43)}=$ $7.214, p<0.05$; ACC, $F_{(3,43)}=6.244, p<0.05$; BLA, $F_{(3,43)}=$ $8.072, p<0.05 ;$ DG, $F_{(3,43)}=2.238, p>0.05 ; \mathrm{LA}, F_{(3,43)}=0.235$, $\left.p>0.05 ; \mathrm{CeA}, F_{(3,43)}=0.695, p>0.05\right)$. The 3 min group showed significantly more c-fos-positive cells in the CA1, CA3, PL, IL, ACC, and BLA regions compared with the other groups (Fig. $3 B-E ; p<0.05)$, whereas the other groups showed comparable numbers of c-fos-positive cells in these brain areas $(p>0.05)$. These results indicated significant $\mathrm{c}$-fos induction in the hippocampal CA1 and CA3, PL, and IL regions of the MPFC, ACC, and BLA region of the amygdala only in the 3 min group (Fig. $3 B-E)$, suggesting that $\mathrm{c}$-fos expression is induced in these brain regions when social recognition memory is generated.

Importantly, in addition to the 3 min group, the 1 min group showed more c-fos-positive cells in the CA1 region than the 0 min and home cage groups, although a significant difference was only observed when compared with the home cage group ( $p<$ $0.05)$, not the 0 min group ( $p>0.05$ ). These results suggest that the hippocampal CA1 region is activated in response to exposure to a juvenile mouse, but shows an exposure-time-dependent increase in c-fos expression.

Similarly, one-way ANOVA revealed significant effects of group on the $\mathrm{OB}$ and MPOA (Fig. $3 F, G$; OB, $F_{(3,43)}=7.355, p<0.05$; MPOA, $\left.F_{(3,43)}=5.031, p<0.05\right)$. In contrast to the results shown above, the 3,1 , and 0 min groups showed significantly more c-fospositive cells in the OB than the home cage group $(p<0.05)$, although the 3,1 , and 0 min groups showed comparable numbers of $c$-fos-positive cells ( $p>0.05$ ), suggesting that exposure to a novel environment is sufficient to induce c-fos expression in the OB. In contrast, the 3 and $1 \mathrm{~min}$ groups showed significantly more c-fospositive cells in the MPOA region than the home cage group $(p<$ 0.05 ), although the 3 and 1 min groups showed comparable numbers of $c$-fos-positive cells ( $p>0.05$ ), suggesting that exposure to a juvenile mouse induces $\mathrm{c}$-fos expression in the MPOA even though exposure duration was only $1 \mathrm{~min}$.

In contrast, one-way ANOVA revealed no significant effect of group on the VC, TC, PRh, and EC (Fig. $3 H$; VC, $F_{(3,43)}=1.704$, $p>0.05 ; \mathrm{TC}, F_{(3,43)}=0.343, p>0.05 ; \mathrm{PRh}, F_{(3,43)}=0.732, p>$ 0.05 ; EC, $\left.F_{(3,43)}=0.865, p>0.05\right)$. These results indicated that c-fos expression is not induced in these cortical regions after exposure to a mouse and/or novel environment.

Together, our anatomical analyses indicated that c-fos expression is induced in the hippocampus, MPFC, ACC, and amygdala when social memory is generated, raising the possibility that gene expression in these brain regions contributes to the formation of social recognition memory.

\section{Induction of Arc expression in multiple brain regions after training for social recognition}

To clarify further the brain regions showing IEG expression after training for social recognition, the expression of another activitydependent gene targeted by CREB, Arc (Kaczmarek and Robertson, 2002, Guzowski et al., 1999, Montag-Sallaz et al., 1999, Guthrie et al., 2000, Kawashima et al., 2009), was measured in the same brain regions of the four groups as above. Similar to the results for c-fos, one-way ANOVA revealed significant effects of group on the CA1, CA3, PL, IL, ACC, BLA, and OB, but not the DG, LA, CeA, MPOA, and cortical regions (Fig. $4 B-H$; CA1, $F_{(3,44)}=6.208, p<0.05 ;$ CA3, $F_{(3,44)}=9.064, p<0.05 ; \mathrm{PL}$, $F_{(3,44)}=21.266, p<0.05 ; \mathrm{IL}, F_{(3,44)}=24.581, p<0.05$; ACC, $F_{(3,44)}=19.487, p<0.05$; BLA, $F_{(3,44)}=11.809, p<0.05$; DG, $\mathrm{F}_{(3.44)}=2.562, p>0.05 ; \mathrm{LA}, F_{(3,44)}=2.710, p>0.05 ; \mathrm{CeA}$, $F_{(3,44)}=1.652, p>0.05 ; \mathrm{OB}, F_{(3,44)}=3.555, p<0.05 ; \mathrm{MPOA}$, $F_{(3,44)}=1.453, p>0.05 ; \mathrm{VC}, F_{(3,44)}=1.384, p>0.05 ;$ TC, $F_{(3,44)}=0.310, p>0.05 ; \mathrm{PRh}, \mathrm{F}_{(3.44)}=2.551, p>0.05 ; \mathrm{EC}$, $\left.F_{(3,44)}=2.123, p>0.05\right)$. Importantly, the 3 min group showed significantly more Arc-positive cells in the CA1, CA3, PL, IL, ACC, and BLA regions than the other groups (Fig. $4 B-E ; p<$ 0.05), suggesting that Arc expression is activated in hippocampal $\mathrm{CA} 1$ and $\mathrm{CA} 3, \mathrm{mPFC}$ (PL and IL), ACC, and BLA of the amygdala when social recognition memory is generated. These results confirmed the results of $\mathrm{c}$-fos expression and suggested that CREBmediated gene expression (Arc and c-fos) is induced in the hippocampus, mPFC, ACC, and amygdala when social recognition memory is formed. In contrast to the results of c-fos expression, the $\mathrm{OB}$ showed significantly more Arc-positive cells in the 3 min group than in the home cage group, but not in the other groups ( $p<0.05$ ), suggesting that $\mathrm{c}-\mathrm{fos}$ and Arc expression is regulated differently in the $\mathrm{OB}$.

\section{Requirement for gene expression in the hippocampus, $\mathrm{mPFC}$, ACC, and amygdala for the consolidation of social recognition memory}

Gene expression in the hippocampus is required for the consolidation of social recognition memory (Kogan et al., 2000; Suzuki et al., 2011). Our gene expression analyses indicated that gene expression is activated in the hippocampus, $\mathrm{mPFC}, \mathrm{ACC}$, and amygdala after social recognition learning, suggesting that new gene expression in these brain regions contributes to the formation of social recognition memory. To test this, we examined the effects of inhibiting protein synthesis in the hippocampus, mPFC, ACC, or amygdala on the formation of social recognition memory. Male mice were exposed to a juvenile male mouse twice for $3 \mathrm{~min}$ at an interval of $2 \mathrm{~h}$ (STM) or $24 \mathrm{~h}$ (LTM). Immediately after the first exposure, the mice received a microinfusion of ANI $(62.5 \mu \mathrm{g})$ or VEH into the brain region under examination. Cannula tip placements are shown in Figures $5 I$ and $6 I$.

One-way ANOVA comparing recognition indexes of STM revealed no significant effect of drug (Fig. 5A, $C, E, G$; hippocampus, $F_{(1,22)}=0.089, p>0.05$; mPFC, $F_{(1,21)}=0.385, p>0.05$; ACC, $F_{(1,22)}=0.195, p>0.05$; amygdala, $F_{(1,20)}=0.193, p>$ $0.05)$. Consistently, the VEH and ANI groups displayed signifi- 
cant decreases in social investigation time at the second exposure compared with the first exposure $(p<0.05)$. These results indicated that all of the ANI groups showed normal STM.

In contrast to the results for STM, one-way ANOVA comparing recognition indexes of LTM revealed significant effects of drug (Fig. 6A, C, E, G; hippocampus, $\mathrm{F}_{(1.22)}=10.292, p<0.05$; $\mathrm{mPFC}, F_{(1,20)}=28.414, p<0.05$; ACC, $F_{(1,24)}=8.940, p<0.05$; amygdala, $\left.F_{(1,21)}=16.887, p<0.05\right)$. The ANI groups displayed a significantly worse recognition index than the VEH group when ANI was microinfused into the hippocampus, mPFC, ACC, or amygdala (Fig. 6A, $C, E, G$; $p<0.05$ ). Consistently, the ANI groups showed comparable social investigation times during the first and second exposures $(p>0.05)$, although the VEH groups showed significant decreases in social investigation time at the second exposure ( $p<0.05$; Fig. $6 B, D, F, H)$. These results indicate that inhibition of protein synthesis in the hippocampus, mPFC, ACC, or amygdala blocks the formation of social recognition LTM.

Our observations that inhibition of protein synthesis in the hippocampus, mPFC, ACC, or amygdala impairs LTM without affecting STM suggest that activation of gene expression in these brain regions is required for the consolidation of social recognition memory. These results confirmed previous findings showing essential roles for the hippocampus in social memory consolidation and extended the observations that the mPFC, ACC, and amygdala are also required for memory consolidation.

\section{Brain network composed of multiple brain regions for the consolidation of social recognition memory}

Memory is not stored in only a single brain area, but in a network composed of multiple regions (Phillips and LeDoux, 1992; Kim et al., 1993; Fanselow and LeDoux, 1999; Zhang et al., 2008; Mamiya et al., 2009; Zhang et al., 2011; Wheeler et al., 2013: Fukushima et al., 2014). Our findings that the formation of social recognition memory requires the activation of gene expression in multiple brain regions led us to analyze functional connectivity by computing covariance across subjects to infer interactions between neural elements (Horwitz et al., 1995; McIntosh, 1999). To do this, we first computed a complete set of interregional correlations in the groups of mice at each time exposure ( 0,1 , or $3 \mathrm{~min})$ using the results of $\mathrm{c}$-fos expression shown in Figure 3 (Fig. 7; Wheeler et al., 2013). Figure $7 A$ shows matrices that display interregional correlations for the number of c-fos-positive cells at each exposure. Increases in higher positive correlations of c-fos expression between two brain regions are observed with exposure time to a juvenile mouse (e.g., the number of red pixels, indicating Pearson's $r \geq 0.6: 0 \mathrm{~min}, 42 ; 1 \mathrm{~min}, 68 ; 3 \mathrm{~min}, 102)$. On the basis of these matrices, we generated network graphs for each exposure where the nodes represent brain regions and the connections between nodes (edges) represent significant correlations $(p<0.05$; Fig. $7 B)$. Changes in network density were observed at a global level with exposure time to a juvenile mouse (number of edges: 0 min, 21; $1 \mathrm{~min}, 41 ; 3 \mathrm{~min}, 54)$. Furthermore, comparisons of Pearson's $r$ value among all brain regions analyzed confirmed these observations and revealed that the 3 min group had significantly increased interregional correlation coefficients compared with the 0 and 1 min groups (Fig. $7 C$, oneway ANOVA, $F_{(2,312)}=22.77, p<0.05$; Newman-Keuls test, $p<0.05)$.

We next examined changes in the connectivity of the brain regions (hippocampus, $\mathrm{MPFC}, \mathrm{ACC}$, and amygdala) required for social recognition LTM with other brain regions (Fig. $7 \mathrm{C}-J$ ). Interestingly, c-fos expression between the hippocampus or
$\mathrm{mPFC}$ and other regions was more strongly correlated in the 3 min group than in the 1 and 0 min group (Fig. $7 D-G$, one-way ANOVA, hippocampus, $F_{(2,114)}=21.56, p<0.05$; mPFC, $F_{(2,78)}=6.8, p<0.05$; Newman-Keuls test, $\left.p<0.05\right)$, suggesting that functional connectivity is increased in the hippocampus and $\mathrm{mPFC}$ when social recognition memory is generated. In contrast, c-fos expression between the ACC or amygdala and other regions showed comparable correlations between the 1 and 3 min groups, but was more correlated in the 1 and 3 min groups compared with the 0 min group, although significantly higher c-fos expression in these regions was observed in the ACC and amygdala of the 3 min group than in the $1 \mathrm{~min}$ group (Fig. $7 \mathrm{H}-\mathrm{K}$, one-way ANOVA, ACC, $F_{(2,39)}=5.08, p<0.05$; amygdala, $F_{(2,114)}=25.04, p<$ 0.05 ; Newman-Keuls test, $p \leq 0.05$ ). In contrast to the results for the hippocampus and mPFC, these observations suggest that exposure to a juvenile mouse is sufficient to increase functional connectivity of the ACC and amygdala with other brain regions.

\section{Identification of social recognition memory network hubs}

We applied graph theoretical analysis to our networks to discover if the relative importance of any of the brain regions changes during the formation of a social recognition memory. We determined brain region importance in two ways. First, we examined how the relative ranking of the centrality measures of degree and betweenness differed in our networks (Fig. 8A,B). Degree is the number of edges that are associated with a given node and betweenness is the number of shortest path lengths in the network on which a node lies (Sporns et al., 2007). Second, we identified the community structure for each network (Fig. $8 \mathrm{C}$ ) and used this to compute the within-community $z$-scores and participation coefficients for each region. Within-community $z$-scores measure how well connected a region is to its own community, whereas the participation coefficient measures how connected a region is to other communities (Guimerà and Amaral, 2005). Regions that are moderately high in both within-community $z$-scores and participation coefficients are considered important hubs that may help to mediate the interactions of disparate parts of a network (Fornito et al., 2015). In the 3 min group, the hippocampus (CA1, CA3, and DG regions) showed a higher rank of both degree and betweenness than in the 0 and 1 min groups (Fig. $8 A, B)$. Furthermore, the DG of the hippocampus had both a high within-community $z$-score and participation coefficient in the 3 min group compared with the 0 and 1 min groups (Fig. 8D). In contrast, the $\mathrm{mPFC}$ regions were lower in both degree and betweenness in the 3 min group compared with the hippocampus, ACC, and amygdala, all of which are required for social recognition LTM. These results suggest that the hippocampus, but not the $\mathrm{MPFC}$, functions as a connector hub to coordinate the interaction of modules within the brain to support social recognition memory. Interestingly, and consistent with the c-fos expression analyses (Fig. $7 I, H$ ), the ACC and amygdala had higher ranks of both degree and betweenness in the 1 min group than in the 0 and 3 min groups (Fig. 8A,B). These regions were also high in both within-community $z$-scores and participation coefficients (Fig. $8 D$ ). These results suggest that the ACC and amygdala play distinct roles from the hippocampus and function as hubs that are important primarily in mediating activation in response to the exposure to a novel mouse.

\section{Discussion}

A critical biochemical feature of memory consolidation is a requirement for gene expression, especially CREB-mediated gene expression (Flexner et al., 1965; Davis and Squire, 1984; 

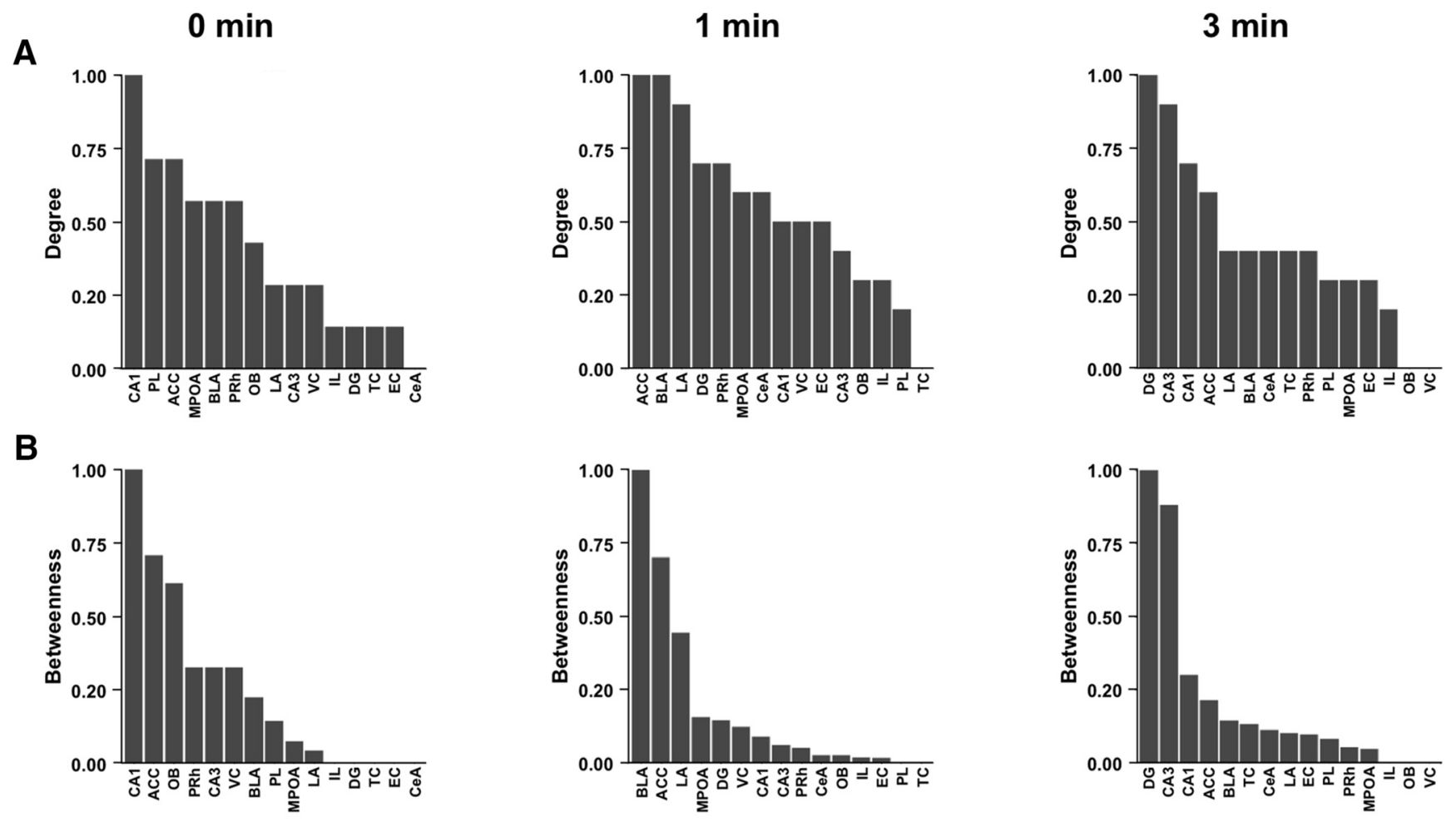

C
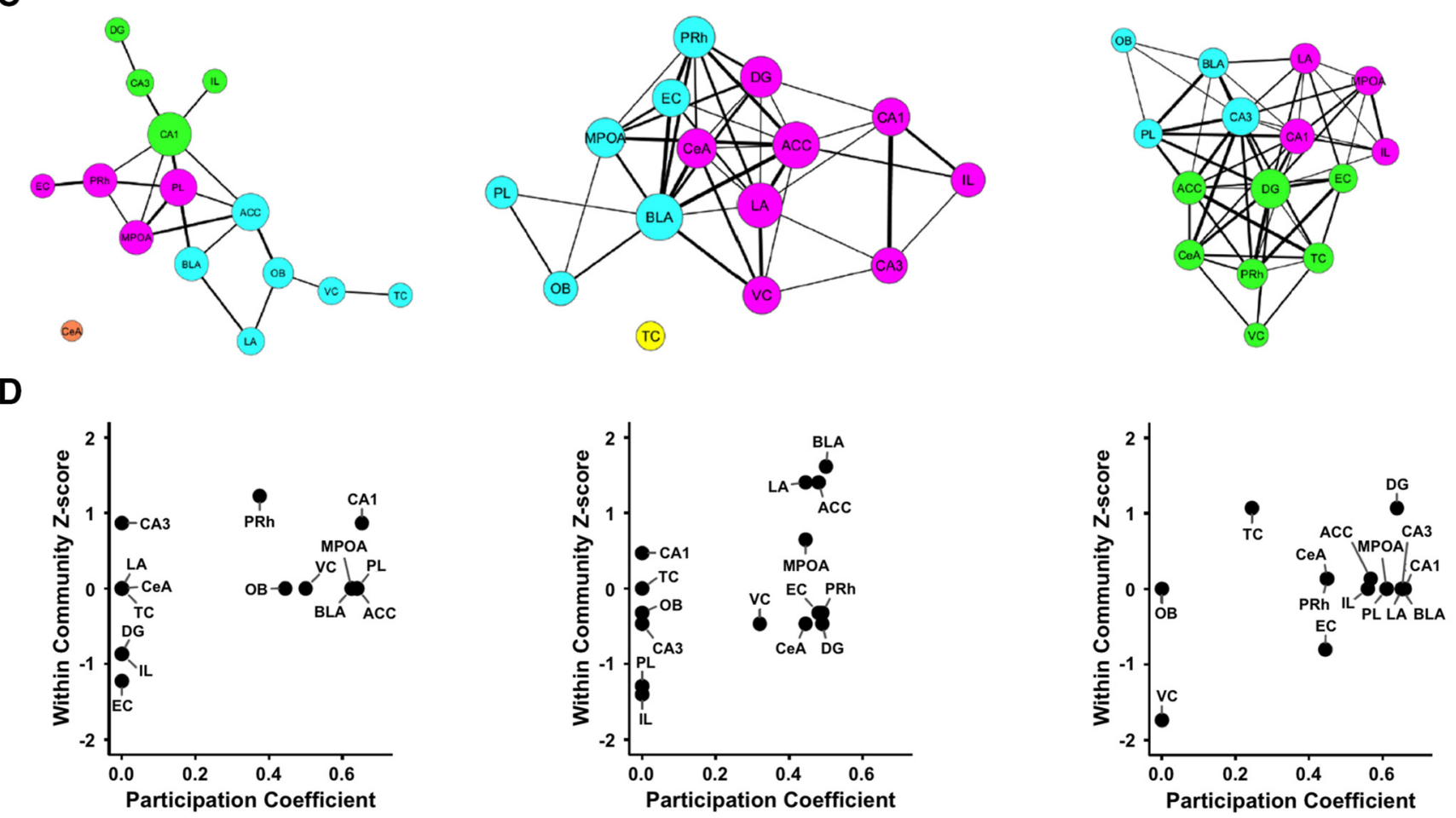

Figure 8. Identification of hub regions in the social recognition memory network. $\boldsymbol{A}, \boldsymbol{B}$, Brain regions ranked in descending order for degree $(\boldsymbol{A})$ and betweenness $(\boldsymbol{B})$. Degree and betweenness are normalized. $C$, Network summarizing functional connections at 0,1 , or 3 min exposure. Colors represent the communities identified via modularity maximization. The widths of the edges are proportional to the strength of the correlations and the size of the nodes is proportional to the degree of the node. $\boldsymbol{D}$, Within-community $z$-scores and participation coefficients for each brain region in the networks.

Bourtchuladze et al., 1994; Abel et al., 1997; Silva et al., 1998; Martin et al., 2000; McGaugh, 2000; Kida et al., 2002; Pittenger et al., 2002; Korzus et al., 2004). In this study, we identified brain regions that play essential roles in the formation of social recognition memory through the activation of gene expression. We first found that CREB-mediated transcription in the forebrain is required for the consolidation of social recognition memory. We next showed that the expression of $\mathrm{c}-$ fos and Arc, which are CREB target genes (Abraham et al., 1993; Worley et al., 1993; Guzowski et al., 1999; Montag-Sallaz et al., 1999; Guthrie et al., 2000; Kac- 
zmarek et al., 2002; Kawashima et al., 2009), is significantly induced in the hippocampus (CA1 and CA3), mPFC (PL and IL), ACC, and amygdala (BLA) (Figs. $3 A-D, 4 A-D$ ) when social recognition memory is generated. Finally, we showed that protein synthesis in these brain areas is required for the consolidation of social recognition memory (Figs. 5, 6). Our findings indicated that the consolidation of social recognition memory depends on new gene expression in the hippocampus, mPFC, ACC, and amygdala. Furthermore, our network analyses using correlations of c-fos expression among brain regions suggest distinct roles for the hippocampus, mPFC, ACC, and amygdala in social recognition memory consolidation. Importantly, the hippocampus may be a connector hub functioning to coordinate the generation of social recognition memory through its interactions with other brain regions.

The hippocampus is a critical region for the formation/consolidation of social recognition memory in mice (Kogan et al., 2000; Suzuki et al., 2011, Hitti and Siegelbaum, 2014). Our results confirmed and supported these previous findings. Interestingly, our network analyses suggested that the hippocampus showed more increases in connectivity with other brain regions compared with the other regions when social recognition memory is generated. Importantly, the hippocampus of the 3 min group showed the highest rank according to both degree and betweenness of functional connectivity and the DG in particular may play an important role in coordinating network activity. These observations suggest that the hippocampus plays a role as a hub to generate social recognition memory by interacting with other brain regions. Interestingly, a recent study by Hitti and Siegelbaum (2014) showed that the hippocampal CA2 region is essential for social recognition memory. It is important to investigate further and compare the roles of hippocampal subregions (CA1, $\mathrm{CA} 2$, and CA3) in social recognition memory because we failed to detect an obvious induction of c-fos and Arc in the CA2 region of the 3 min group (data not shown).

Similar to the hippocampus, our biochemical and behavioral results showed that the $\mathrm{mPFC}$ plays an essential role in the consolidation of social recognition memory. Furthermore, the $\mathrm{mPFC}$ is also suggested to increase connectivity with other brain regions when social recognition memory is formed. However, in contrast to the hippocampus, the mPFC was not ranked highly according to the degree and betweenness of connectivity during the consolidation of social recognition memory compared with the hippocampus, ACC, and amygdala. These observations suggest that the mPFC is a critical brain region for the formation of social recognition memory, but plays a different role to the hippocampus. Importantly, previous studies have shown that the $\mathrm{mPFC}$ is involved in the regulation of social behaviors (Jodo et al., 2010; Yizhar et al., 2011; Felix-Ortiz et al., 2016). Changes in the neuronal activity of the $\mathrm{mPFC}$ are correlated with social approach and interaction (Jodo et al., 2010). Consistently, social approach/ interaction are blocked by an imbalance of excitation and inhibition in the mPFC (Yizhar et al., 2011). Together, these findings indicate that the $\mathrm{mPFC}$ is a critical brain region regulating both social approach/interaction and social recognition memory, suggesting that the mPFC plays central roles in social behaviors. The $\mathrm{mPFC}$ may contribute to social recognition/discrimination by referring to previously consolidated social recognition memory.

We showed that, in addition to the hippocampus and $\mathrm{mPFC}$, gene expression in the amygdala and ACC is required for the consolidation of social recognition memory (Figs. $5 E, F, 6 E, F$ ). However, in contrast to the results for the hippocampus and $\mathrm{mPFC}$, the amygdala and ACC did not show further increases in connectivity even when exposure time to a juvenile mouse was increased (Fig. $7 F-I, 3$ vs 1 min group). Consistently, the ACC and amygdala of the 1 min group showed the highest rank in both the degree and betweenness of functional connectivity and were identified as important hubs based on the community structure of the network. This suggests that the ACC and amygdala are important for coordinating brain activity when social interaction is initiated. Similar to our findings, previous studies using rats showed that blocking protein synthesis or the $\beta$-adrenoreceptor or activating the $\mathrm{D} 1 / \mathrm{D} 5$ dopamine receptor or $\mathrm{H} 2$ histaminergic receptor (Garrido Zinn et al., 2016) in the BLA impairs the formation of social recognition memory. Lesioning of the ACC impairs social recognition STM in mice (Rudebeck et al., 2007). More importantly, the BLA-ventral hippocampus and BLA$\mathrm{mPFC}$ pathways regulate social interaction (Felix-Ortiz and Tye, 2014; Felix-Ortiz et al., 2016). Consistently, electrophysiological recordings revealed changes in neuronal activity in the BLA during social interaction (Katayama et al., 2009). In addition to these rodent studies, neuroimaging studies in humans suggest that the amygdala plays a functional role in social processing and cognition (Killgore and Yurgelun-Todd, 2005; Schultz, 2005; Bickart et al., 2011) and that the ACC is active when participants engage in social interaction (Frith et al., 1999; Rilling et al., 2002; Rilling et al., 2004). Lesioning the ACC in macaques impairs social interaction (Hadland et al., 2003; Rudebeck et al., 2006). Together, these findings suggested that the ACC and amygdala are not only required for the consolidation of social recognition memory, but may also play regulatory roles in social interaction.

Previous studies have shown that activation of gene expression in the hippocampus and amygdala is required for consolidation of contextual fear memory. More importantly, previous work using a combination of c-fos expression and network analyses found that long-term contextual fear memory is stored in a brain network that has a thalamic-hippocampal-cortical signature (Wheeler et al., 2013). In addition, mPFC and thalamus may function as a hub-like region that plays privileged roles in memory expression (Wheeler et al., 2013). Together with our findings in this study, social recognition and contextual fear memories display distinct brain networks to memory formation/recall, suggesting that distinct types of memory show their own functional memory networks. Further studies focusing on other types of memory such as spatial and object recognition memories are required to understand brain networks for memory storages.

Mice discriminate familiar and novel mice based on social recognition memory (Kogan et al., 2000; Fig. 1). Although we identified brain networks among the hippocampus, mPFC, ACC, and amygdala to generate social recognition memory, the brain systems that allow for the discrimination of the familiar and novel still remain unknown. In the future, it will be important to examine and compare neuronal activity and activation of gene expression in those brain regions during and after exposure to familiar and novel mice.

In this study, we found that the consolidation of social recognition memory requires CREB-mediated transcription. Importantly, we showed that the expression of CREB-target IEGs (c-fos and Arc) was induced in the hippocampus, mPFC, ACC, and amygdala when social recognition memory was generated. Consistently, we showed that new gene expression in these brain regions was required for the consolidation of social recognition memory. These findings suggest that social recognition memory is encoded in a network of these brain regions. Furthermore, our network analyses suggest that the hippocampus, mPFC, ACC, and amygdala show distinct roles in learning and memory of 
social recognition and, importantly, that the hippocampus functions as a connector hub to generate social recognition memory by coordinating regional interactions.

\section{References}

Abel T, Nguyen PV, Barad M, Deuel TA, Kandel ER, Bourtchouladze R (1997) Genetic demonstration of a role for PKA in the late phase of LTP and in hippocampus-based long-term memory. Cell 88:615-626. CrossRef Medline

Abraham WC, Mason SE, Demmer J, Williams JM, Richardson CL, Tate WP, Lawlor PA, Dragunow M (1993) Correlations between immediate early gene induction and the persistence of long-term potentiation. Neuroscience 56:717-727. CrossRef Medline

Berry RJ, Bronson FH (1992) Life history and bioeconomy of the house mouse. Biol Rev Camb Philos Soc 67:519-550. Medline

Bickart KC, Wright CI, Dautoff RJ, Dickerson BC, Barrett LF (2011) Amygdala volume and social network size in humans. Nat Neurosci 14: 163-164. CrossRef Medline

Bourtchuladze R, Frenguelli B, Blendy J, Cioffi D, Schutz G, Silva AJ (1994) Deficient long-term memory in mice with a targeted mutation of the cAMP-responsive element-binding protein. Cell 79:59-68. CrossRef Medline

Colgan, P (1983) Comparitive social recognition. Canada: Wiley.

Csardi G, Nepusz T (2006) The igraph software package for complex network research. InterJournal, Complex Syst 1695:1-9.

Davis HP, Squire LR (1984) Protein synthesis and memory. Psychol Bull 96:518-559. CrossRef Medline

Dudai Y (1996) Consolidation, fragility and the road to the engram. Neuron 17:367-370. CrossRef Medline

Fanselow MS, LeDoux JE (1999) Why we think plasticity underlying Pavlovian fear conditioning occurs in the basolateral amygdala. Neuron 23: 229-232. CrossRef Medline

Felix-Ortiz AC, Tye KM (2014) Amygdala inputs to the ventral hippocampus bidirectionally modulate social behavior. J Neurosci 34:586-595. CrossRef Medline

Felix-Ortiz AC, Burgos-Robles A, Bhagat ND, Leppla CA, Tye KM (2016) Bidirectional modulation of anxiety-related and social behaviors by amygdala projections to the medial prefrontal cortex. Neuroscience 321: 197-209. CrossRef Medline

Flexner LB, Flexner JB, Stellar E (1965) Memory and cerebral protein synthesis in mice as affected by graded amounts of puromycin. Exp Neurol 13:264-272. CrossRef Medline

Fornito A, Zalesky A, Breakspear M (2015) The connectomics of brain disorders. Nat Rev Neurosci 16:159-172. CrossRef Medline

Frankland PW, Bontempi B, Talton LE, Kaczmarek L, Silva AJ (2004) The involvement of the anterior cingulate cortex in remote contextual fear memory. Science 304:881-883. CrossRef Medline

Frankland PW, Ding HK, Takahashi E, Suzuki A, Kida S, Silva AJ (2006) Stability of recent and remote contextual fear memory. Learn Mem 13: 451-457. CrossRef Medline

Franklin KB, Paxinos G (1997) The mouse brain in stereotaxic coordinates. San Diego: Elsevier Academic.

Frith CD, Frith U (1999) Interacting minds: a biological basis. Science 286: 1692-1695. CrossRef Medline

Fukushima H, Maeda R, Suzuki R, Suzuki A, Nomoto M, Toyoda H, Wu LJ, Xu H, Zhao MG, Ueda K, Kitamoto A, Mamiya N, Yoshida T, Homma S, Masushige S, Zhuo M, Kida S (2008) Upregulation of calcium/ calmodulin-dependent protein kinase IV improves memory formation and rescues memory loss with aging. J Neurosci 28:9910-9919. CrossRef Medline

Fukushima H, Zhang Y, Archbold G, Ishikawa R, Nader K, Kida S (2014) Enhancement of fear memory by retrieval through reconsolidation. Elife 3:e02736. CrossRef Medline

Gabor CS, Phan A, Clipperton-Allen AE, Kavaliers M, Choleris E (2012) Interplay of oxytocin, vasopressin, and sex hormones in the regulation of social recognition. Behav Neurosci 126:97-109. CrossRef Medline

Garrido Zinn C, Clairis N, Silva Cavalcante LE, Furini CR, de Carvalho Myskiw J, Izquierdo I (2016) Major neurotransmitter systems in dorsal hippocampus and basolateral amygdala control social recognition memory. Proc Natl Acad Sci U S A 113:E4914-4919. CrossRef Medline

Guimaraes IM, Carvalho TG, Ferguson SS, Pereira GS, Ribeiro FM (2015)
The metabotropic glutamate receptor 5 role on motor behavior involves specific neural substrates. Mol Brain 8:24. CrossRef Medline

Guimerà R, Amaral LA (2005) Cartography of complex networks: modules and universal roles. J Stat Mech 2005(P02001):nihpa35573. Medline

Guthrie K, Rayhanabad J, Kuhl D, Gall C (2000) Odors regulate Arc expression in neuronal ensembles engaged in odor processing. Neuroreport 11:1809-1813. CrossRef Medline

Guzowski JF, McNaughton BL, Barnes CA, Worley PF (1999) Environment-specific expression of the immediate-early gene Arc in hippocampal neuronal ensembles. Nat Neurosci 2:1120-1124. CrossRef Medline

Guzowski JF, Setlow B, Wagner EK, McGaugh JL (2001) Experiencedependent gene expression in the rat hippocampus after spatial learning: a comparison of the immediate-early genes Arc, c-fos, and zif268. J Neurosci 21:5089-5098. Medline

Hadland KA, Rushworth MF, Gaffan D, Passingham RE (2003) The effect of cingulate lesions on social behaviour and emotion. Neuropsychologia 41:919-931. CrossRef Medline

Hitti FL, Siegelbaum SA (2014) The hippocampal CA2 region is essential for social memory. Nature 508:88-92. CrossRef Medline

Horwitz B, McIntosh AR, Haxby JV, Grady CL (1995) Network analysis of brain cognitive function using metabolic and blood flow data. Behav Brain Res 66:187-193. CrossRef Medline

Inaba H, Tsukagoshi A, Kida S (2015) PARP-1 activity is required for the reconsolidation and extinction of contextual fear memory. Mol Brain 8:63. CrossRef Medline

Inaba H, Kai D, Kida S (2016a) N-glycosylation in the hippocampus is required for the consolidation and reconsolidation of contextual fear memory. Neurobiol Learn Mem 135:57-65. CrossRef Medline

Inaba $\mathrm{H}$, Kishimoto $\mathrm{T}$, Oishi $\mathrm{S}$, Nagata $\mathrm{K}$, Hasegawa $\mathrm{S}$, Watanabe $\mathrm{T}$, Kida $\mathrm{S}$ (2016b) Vitamin B1-deficient mice show impairment of hippocampusdependent memory formation and loss of hippocampal neurons and dendritic spines: potential microendophenotypes of Wernicke-Korsakoff syndrome. Biosci Biotechnol Biochem 80:2425-2436. CrossRef Medline

Ishikawa R, Kim R, Namba T, Kohsaka S, Uchino S, Kida S (2014) Time-dependent enhancement of hippocampus-dependent memory after treatment with memantine: Implications for enhanced hippocampal adult neurogenesis. Hippocampus 24:784-793. CrossRef Medline

Jiming F, Hurst J, Barnard C (1994) Behaviours among adult fellow group members of wild house mice. Acta Theriol Sin 14:221-233.

Jodo E, Katayama T, Okamoto M, Suzuki Y, Hoshino K, Kayama Y (2010) Differences in responsiveness of mediodorsal thalamic and medial prefrontal cortical neurons to social interaction and systemically administered phencyclidine in rats. Neuroscience 170:1153-1164. CrossRef Medline

Josselyn SA, Kida S, Silva AJ (2004) Inducible repression of CREB function disrupts amygdala-dependent memory. Neurobiol Learn Mem 82:159_ 163. CrossRef Medline

Kaczmarek L, Robertson HA (2002) Handbook of chemical neuroanatomy. Amsterdam: Elsevier.

Katayama T, Jodo E, Suzuki Y, Hoshino KY, Takeuchi S, Kayama Y (2009) Phencyclidine affects firing activity of basolateral amygdala neurons related to social behavior in rats. Neuroscience 159:335-343. CrossRef Medline

Kawashima T, Okuno H, Nonaka M, Adachi-Morishima A, Kyo N, Okamura M, Takemoto-Kimura S, Worley PF, Bito H (2009) Synaptic activityresponsive element in the Arc/Arg3.1 promoter essential for synapsetonucleus signaling in activated neurons. Proc Natl Acad Sci U S A 106: 316-321. CrossRef Medline

Kida S, Josselyn SA, Peña de Ortiz S, Kogan JH, Chevere I, Masushige S, Silva AJ (2002) CREB required for the stability of new and reactivated fear memories. Nat Neurosci 5:348-355. CrossRef Medline

Killgore WD, Yurgelun-Todd DA (2005) Social anxiety predicts amygdala activation in adolescents viewing fearful faces. Neuroreport 16:16711675. CrossRef Medline

Kim JJ, Rison RA, Fanselow MS (1993) Effects of amygdala, hippocampus and periaqueductal gray lesions on short- and long-term contextual fear. Behav Neurosci 107:1093-1098. CrossRef Medline

Kitamura T, Okubo-Suzuki R, Takashima N, Murayama A, Hino T, Nishizono H, Kida S, Inokuchi K (2012) Hippocampal function is not required for the precision of remote place memory. Mol Brain 5:5. CrossRef Medline 
Kogan JH, Frankland PW, Silva AJ (2000) Long-term memory underlying hippocampus-dependent social recognition in mice. Hippocampus 10: 47-56. CrossRef Medline

Korzus E, Rosenfeld MG, Mayford M (2004) CBP histone acetyltransferase activity is a critical component of memory consolidation. Neuron 42:961972. CrossRef Medline

Lai WS, Ramiro LL, Yu HA, Johnston RE (2005) Recognition of familiar individuals in golden hamsters: a new method and functional neuroanatomy. J Neurosci 25:11239-11247. CrossRef Medline

Mamiya N, Fukushima H, Suzuki A, Matsuyama Z, Homma S, Frankland PW, Kida S (2009) Brain region-specific gene expression activation required for reconsolidation and extinction of contextual fear memory. J Neurosci 29:402-413. CrossRef Medline

Martin SJ, Grimwood PD, Morris RG (2000) Synaptic plasticity and memory: an evaluation of the hypothesis. Annu Rev Neurosci 23:649-711. CrossRef Medline

McGaugh JL (2000) Memory-a century of consolidation. Science 287:248251. CrossRef Medline

McIntosh AR (1999) Mapping cognition to the brain through neural interactions. Memory 7:523-548. CrossRef Medline

Montag-Sallaz M, Welzl H, Kuhl D, Montag D, Schachner M (1999) Novelty-induced increased expression of immediate-early genes c-fos and $\arg 3.1$ in the mouse brain. J Neurosci 38:234-246. Medline

Morrow BA, Elsworth JD, Inglis FM, Roth RH (1999) An antisense oligonucleotide reverses the footshock-induced expression of Fos in the rat medial prefrontal cortex and the subsequent expression of conditioned fear-induced immobility. J Neurosci 19:5666-5673. Medline

Newman ME, Girvan M (2004) Finding and evaluating community structure in networks. Phys Rev E Stat Nonlin Soft Matter Phys 69:026113. CrossRef Medline

Nomoto M, Takeda Y, Uchida S, Mitsuda K, Enomoto H, Saito K, Choi T, Watabe AM, Kobayashi S, Masushige S, Manabe T, Kida S (2012) Dysfunction of the RAR/RXR signaling pathway in the forebrain impairs hippocampal memory and synaptic plasticity. Mol Brain 5:8. CrossRef Medline

Phillips RG, LeDoux JE (1992) Differential contribution of amygdala and hippocampus to cued and contextual fear conditioning. Behav Neurosci 106:274-285. CrossRef Medline

Pittenger C, Huang YY, Paletzki RF, Bourtchouladze R, Scanlin H, Vronskaya S, Kandel ER (2002) Reversible inhibition of CREB/ATF transcription factors in region CAl of the dorsal hippocampus disrupts hippocampusdependent spatial memory. Neuron 34:447-462. CrossRef Medline

Rilling JK, Sanfey AG, Aronson JA, Nystrom LE, Cohen JD (2004) The neural correlates of theory of mind within interpersonal interactions. Neuroimage 22:1694-1703. CrossRef Medline

Rilling J, Gutman D, Zeh T, Pagnoni G, Berns G, Kilts C (2002) A neural basis for social cooperation. Neuron 35:395-405. CrossRef Medline

Rosenblum K, Meiri N, Dudai Y (1993) Taste memory: the role of protein synthesis in gustatory cortex. Behav Neural Biol 59:49-56. CrossRef Medline

Rudebeck PH, Buckley MJ, Walton ME, Rushworth MF (2006) A role for the macaque anterior cingulate gyrus in social valuation. Science 313: 1310-1312. CrossRef Medline

Rudebeck PH, Walton ME, Millette BH, Shirley E, Rushworth MF, Banner- man DM (2007) Distinct contributions of frontal areas to emotion and social behaviour in the rat. Eur J Neurosci 26:2315-2326. Medline

Santini E, Ge H, Ren K, Peña de Ortiz S, Quirk GJ (2004) Consolidation of fear extinction requires protein synthesis in the medial prefrontal cortex. J Neurosci 24:5704-5710. CrossRef Medline

Schultz RT (2005) Developmental deficits in social perception in autism: the role of the amygdala and fusiform face area. Int J Dev Neurosci 23: 125-141. CrossRef Medline

Shannon P, Markiel A, Ozier O, Baliga NS, Wang JT, Ramage D, Amin N, Schwikowski B, Ideker T (2003) Cytoscape: a software environment for integrated models of biomolecular interaction networks. Genome Res 13:2498-2504. CrossRef Medline

Sheng M, McFadden G, Greenberg ME (1990) Membrane depolarization and calcium induce $\mathrm{c}$-fos transcription via phosphorylation of transcription factor CREB. Neuron 4:571-582. CrossRef Medline

Silva AJ, Kogan JH, Frankland PW, Kida S (1998) CREB and memory. Annu Rev Neurosci 21:127-148. CrossRef Medline

Sporns O, Honey CJ, Kötter R (2007) Identification and classification of hubs in brain networks. PLoS One 2:e1049. CrossRef Medline

Squire LR, Alvarez P (1995) Retrograde amnesia and memory consolidation: a neurobiological perspective. Curr Opin Neurobiol 5:169-177. CrossRef Medline

Suzuki A, Mukawa T, Tsukagoshi A, Frankland PW, Kida S (2008) Activation of LVGCCs and CB1 receptors required for destabilization of reactivated contextual fear memories. Learn Mem 15:426-433. CrossRef Medline

Suzuki A, Fukushima H, Mukawa T, Toyoda H, Wu LJ, Zhao MG, Xu H, Shang Y, Endoh K, Iwamoto T, Mamiya N, Okano E, Hasegawa S, Mercaldo V, Zhang Y, Maeda R, Ohta M, Josselyn SA, Zhuo M, Kida S (2011) Upregulation of CREB-mediated transcription enhances both short- and long-term memory. J Neurosci 31:8786-8802. CrossRef Medline

Thor DH, Holloway WR (1982) Social memory of the male laboratory rat. J Comp Physiol Psychol 96:1000-1006. CrossRef

Wheeler AL, Teixeira CM, Wang AH, Xiong X, Kovacevic N, Lerch JP, McIntosh AR, Parkinson J, Frankland PW (2013) Identification of a functional connectome for long-term fear memory in mice. PLoS Comput Biol 9:e1002853. CrossRef Medline

Worley PF, Bhat RV, Baraban JM, Erickson CA, McNaughton BL, Barnes CA (1993) Thresholds for synaptic activation of transcription factors in hippocampus: correlation with long-term enhancement. J Neurosci 13: 4776-4786. Medline

Yizhar O, Fenno LE, Prigge M, Schneider F, Davidson TJ, O'Shea DJ, Sohal VS, Goshen I, Finkelstein J, Paz JT, Stehfest K, Fudim R, Ramakrishnan C, Huguenard JR, Hegemann P, Deisseroth K (2011) Neocortical excitation/inhibition balance in information processing and social dysfunction. Nature 477:171-178. CrossRef Medline

Zhang XH, Wu LJ, Gong B, Ren M, Li BM, Zhuo M (2008) Induction- and conditioning-protocol dependent involvement of NR2B-containing NMDA receptors in synaptic potentiation and contextual fear memory in the hippocampal CA1 region of rats. Mol Brain 1:9. CrossRef Medline

Zhang Y, Fukushima H, Kida S (2011) Induction and requirement of gene expression in the anterior cingulate cortex and medial prefrontal cortex for the consolidation of inhibitory avoidance memory. Mol Brain 4:4. CrossRef Medline 